\title{
La libre competencia económica y la protección del medio ambiente: Una aproximación al estudio de los Acuerdos Voluntarios de Cumplimiento Ambiental ${ }^{1}$
}

Free Economic Competition and Environmental Protection: An approach to the study of Environmental Compliance Voluntary Agreements

\section{Ingrid S. ORTIZ BAquero² \\ Diego A. Solano Osorio ${ }^{3}$}

El presente artículo tiene por objeto ilustrar la compatibilización entre dos bienes jurídicos de tutela en el orden económico internacional, el derecho a un medio ambiente sano y ellibre ejercicio de la competencia económica,

1 Fecha de recepción: 15 de febrero de 2016. Fecha de aceptación: 21 de junio de 2016. Para citar el artículo: Ortiz, I. y Solano, D. "La Libre Competencia Económica y la Protección del Medio Ambiente: Una aproximación al estudio de los Acuerdos Voluntarios de Cumplimiento Ambiental". Revist@ E-Mercatoria, vol. 15, N 1, enero-junio, 2016. DOI: https://doi.org/10.18601/16923960.v15n1.01

2 Doctora en Derecho Mercantil de la Universidad Autónoma de Madrid. Docente investigadora del Departamento de Derecho Comercial de la Universidad Externado de Colombia. Correo Electrónico ingrido.ortiz@uexternado.edu.co.

3 Abogado especialista en Derecho Comercial de la Universidad Externado de Colombia, con Curso de Perfeccionamiento en Derecho de la Competencia de la misma institución. Asistente de Investigación del Departamento de Derecho Comercial de la Universidad Externado de Colombia, y Legal Assistant en la Compañía British American Tobacco. Correo Electrónico: diego.solano@uexternado.edu.co. 
mediante la introducción de acuerdos voluntarios de cumplimiento de normas ambientales, haciendo ver que mediante con estos mecanismos se puede lograr una compatibilización de las dos finalidades que de antaño han sido consideradas diametralmente opuestas. Se trata de un estudio, del sistema europeo, donde estos se han desarrollado y se encuentran en camino de consolidación, analizando las ventajas que estos representan, así como, las preocupaciones que han traído para las autoridades de competencia, la ejecución de los mismos en un ámbito práctico y la posible afectación a la competencia. Por último, se pretende abordar, la eventual introducción de estos en el sistema jurídico colombiano, las normas que los habilitarían, para con ello, lograr la sinergia entre libre competencia y protección del medio ambiente.

Palabras Claves: Medio ambiente, libre competencia económica, acuerdos voluntarios, reglamentos de exención por categoría, acuerdos de cooperación horizontal.

\section{ABSTRACT}

This article pretends to illustrate the compatibility between two actual legal interests in the international economic order, the right to a healthy environment and the right of a free exercise of economic competition, by introducing voluntary agreements of compliance with environmental standards, making see that through these mechanisms can achieve compatibility of the two goals that once were considered diametrically opposed. This is an European system analysis, where these have been developed and are on track to consolidating, checking the advantages they would represent for the economy, as well as the concerns that have brought to the competition authorities, executing them in a practical scope and possible effects on the market. Finally, it aims to tackle the possible introduction of these in the Colombian legal system that would enable the rules to thereby achieve synergy between competition and environmental protection.

Key words: Environment, Voluntary agreements, economic competition, block exemption regulation, horizontal co-operation agreements.

\section{INTRODUCCIÓN}

Tanto la libre competencia económica como el derecho a un medio ambiente sano han sido catalogados como derechos colectivos, es decir, derechos que pertenecen a todos y que generan una serie de beneficios que impactan en el bienestar general. 
Cuando estos derechos han resultado en conflicto, las decisiones tanto de las autoridades administrativas como judiciales han estado orientadas generalmente a privilegiar el medio ambiente sobre la libertad de las empresas de concurrir al mercado. Bajo esta visión tradicional se considera que la protección al medio ambiente sano constituye uno de los límites que legítimamente puede invocar el legislador para establecer condiciones y restricciones a las libertades económicas y, en especial a la libertad de competencia.

Europa discurrió por este camino que consideramos tradicional durante muchos años; sin embargo, al comprender que los problemas de medio ambiente son los problemas de las empresas, del mercado y de los consumidores y sobre todo que la regulación y los procedimientos sancionatorios no son la única herramienta válida para promover el cumplimiento de las normas ambientales, ha dado un giro a través del cual pretende lograr la compatibilización de la actividad empresarial y el desarrollo económico con la protección del medio ambiente, precisamente por esta razón se introdujo en instrumentos comunitarios e internacionales el concepto de desarrollo sostenible.

De manera más reciente, las autoridades europeas han querido que la compatibilidad entre los derechos mencionados se construya desde la competencia económica en los mercados, haciendo que la protección al medio ambiente no sea un límite a la libertad de competencia sino un fin de la misma.

Este artículo pretende ilustrar la manera en que las normas de protección al medio ambiente han sido introducidos dentro de los bienes jurídicos objeto de protección por parte del derecho de la libre competencia. Así mismo, busca evidenciar los instrumentos a partir de los cuales las autoridades europeas han logrado crear los incentivos necesarios para promover la celebración de acuerdos que generan beneficios desde la perspectiva ambiental y a través de los cuales las empresas aumentan sus compromisos por encima de los rangos legales. Dentro de estos instrumentos nos referiremos al sistema de excepción aplicable a los acuerdos que pese a tener efectos restrictivos en la competencia, generan o están orientados a crear beneficios desde el punto de vista ambiental y la utilidad de los mismos dentro del mercado.

En búsqueda de ello nos referiremos en una primera parte a los fines de las normas anticompetitivas y a la manera en que la protección del medio ambiente se ha introducido como un fin del derecho antimonopolio. En la segunda parte se explican de forma sucinta el régimen general de prohibición de las conductas anticompetitivas y el sistema de exención en el Derecho Europeo de la Competencia con el fin de comprender el marco general dentro del cual se pueden analizar los pactos o acuerdos empresariales. En la tercera parte abordaremos los denominados acuerdos voluntarios de cumplimiento ambiental como el instrumento que por excelencia logra una sinergia entre antitrust y medio ambiente. Finalmente, en una cuarta parte del trabajo, abordaremos el estudio de los temas agotados en los capítulos anteriores pero orientados 
o valorados desde la normativa y la perspectiva del derecho de la libre competencia en Colombia.

\section{LA LIBRE COMPETENCIA Y SU COMPATIBILIZACIÓN CON LA PROTECCIÓN AL MEDIO AMBIENTE}

\section{Los Presupuestos de la Ilicitud Antitrust}

Determinar que una conducta es ilícita implica establecer que ella contraviene los valores y lesiona los bienes jurídicos que el legislador (comunitario o nacional) intenta proteger a través de una determinada normativa. En el ámbito del derecho antitrust o antimonopolio esto significa que la prohibición y la sanción de las conductas contrarias a la libre competencia (ilícitos antitrust o anticoncurrenciales) se justifica en cuanto tales comportamientos lesionan o contravienen los principios y valores de orden constitucional económico que han sido reiterados en las normas legales y reglamentarias.

Así pues, resulta imprescindible establecer los valores y bienes jurídicos que soportan el sistema de economía social de mercado ${ }^{4}$ porque son ellos los que sirven de sustrato al modelo social de competencia ${ }^{5}$ y justifican la creación de un sistema de normas antimonopolio. Estos principios y valores son los siguientes:

1. La libertad entendida como la posibilidad de ingreso, permanencia y salida del mercado dentro de los límites trazados por la propia Constitución y la ley, entre otros, la intervención del Estado, la planificación, el interés general y los derechos ajenos ${ }^{6}$.

4 Entre otras características de este modelo destacan: (i) la protección de las libertades económicas junto al reconocimiento de la importancia y la necesidad de la intervención

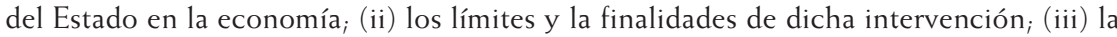
reserva de determinadas actividades a favor de entidades estatales; (iv) los límites impuestos al ejercicio de libertades y derechos económicos por razones de interés general, (v) la protección y defensa de los consumidores y usuarios y (vi) la garantía del orden público económico. Sobre las características de este modelo pude verse Broseta Pont, Manuel. Manual de Derecho Mercantil. Madrid: Tecnos. 2007, 14. ${ }^{\text {a }}$ ed., Vol. I, p. 161.

5 De Eizaguirre, José María. Derecho Mercantil. Madrid: Thomson Civitas, 2005, $4^{a}$ Ed.,pp. 324-327; Font Galán, Juan Ignacio, "Notas sobre el modelo económico de la constitución española de 1978", Revista de Derecho Mercantil, No. 151, 1979, pp. 205-239; Rojo, Ángel. "Actividad económica pública y actividad económica privada en la constitución española". Revista de Derecho Mercantil, Nos. 169-170, julio-diciembre, 1983, pp. 309-341.

6 Baylos Corroza, Hermenegildo, Tratado de Derecho Industrial, Madrid: Civitas, 1993, p. 262 señala que la libertad como valor debe ser entendida de dos de sus facetas, por un lado, la libertad de los competidores y, de otro, la libertad de los consumidores. Con el mismo alcance véase Calvo Caravaca, Alfonso-Luis y Fernández de la Gándara, Luis, "Política y Derecho de la Competencia en la C.E.E: Una aproximación", Revista General del Derecho, No. 583, 1993, p. 338: "(...) Para poder hablar en rigor de competencia se hace inexcu- 
2. La igualdad vista inicialmente como la paridad entre las iniciativas privadas y las públicas y también como el mantenimiento de las condiciones materiales y regulatorias bajo las cuales se desenvuelve la actividad competitiva ${ }^{7}$.

3. La eficiencia como valor y fin. Como valor sustenta la operatividad de los mecanismos de excepción, es decir, la sustracción del ámbito de la prohibición de aquellas conductas cuyos efectos pese a su naturaleza restrictiva son para el mercado más positivos que negativos. Y como fin, puede estar referida tanto a la asignación de recursos como al bienestar de los consumidores ${ }^{8}$.

4. La lealtad, entendida como competencia basada en los propios méritos también considerada como competencia por eficiencia. Debemos entender que la lucha en el mercado debe suscitar la mejora de las prestaciones ofrecidas al consumidor y que el empresario debe estar constantemente preocupado por mejorar su actividad, siendo ese esfuerzo propio, constante y respetuoso de los límites trazados para el ejercicio de la libre competencia, definitivo para el mantenimiento de la rivalidad ${ }^{9}$.

Atenta a estos valores, la Constitución Colombiana define los rasgos esenciales de la libre competencia económica así como la finalidad y los límites dentro de los que resulta posible su regulación y restricción.

En efecto, dentro de la economía social de mercado, la libre competencia económica entendida como manifestación y contenido esencial de la libertad de empresa (art. $333 \mathrm{CP}$ ) y del orden público económico ${ }^{10}$, no se considera un valor en sí mismo, sino un medio a través del que se obtienen beneficios de distinta naturaleza a favor de la comunidad, del mercado mismo y de los

sable, entre otros requisitos, la posibilidad para cada nueva empresa, de introducirse en un mercado en el que no ha operado con anterioridad (principio del mercado abierto), sin que tal acceso se vea obstaculizado por barreras de entrada artificiales; la posibilidad asimismo de que los operadores económicos ya instalados decidan libremente su política empresarial, atendiendo exclusivamente a datos tales como la situación del mercado, la relación costes-beneficios o el comportamiento de las otras empresas que operan en el mismo sector de la actividad (principio de la autonomía de la estrategia empresarial); la posibilidad finalmente de que los consumidores, destinatarios finales del proceso productivo, opten libremente entre aquellos bienes y servicios que prefieran en atención a su precio, a su calidad o a otras circunstancias económicas (...) (principio de la soberanía del consumidor)".

7 Garrigues, Joaquín, La defensa de la competencia mercantil, Madrid: Sociedad de Estudios y publicaciones, 1964, p. 12.

8 Guidini, Gustavo, Aspectos Actuales del Derecho Industrial. Propiedad Intelectual y Competencia, Granada: Comares, 2002, p. 187.

9 Illescas, Rafael, Derecho de la competencia: La libre competencia. Jiménez Sánchez Guillermo J. (coord.), Derecho Mercantil, Barcelona: Ariel, 2006, $11^{\text {a }}$ ed., capítulo 38, p. 726; Bercovitz, Alberto, Apuntes de Derecho Mercantil, op. cit., p. 390.

10 Véase Sainz Moreno y Fernando. Orden público y restricciones de la competencia, Revistas de las Administraciones Públicas, No. 84, 1977, pp. 597-640; Sainz Moreno, Fernando. El principio de libre competencia como manifestación del orden público económico. Revistas Española de Derecho Administrativo, No. 24, 1980, pp. 134-138. 
distintos operadores económicos que se desenvuelven en él (empresarios, consumidores y usuarios) ${ }^{11}$.

Por esta misma razón se considera que la libertad de empresa y su núcleo, la libre competencia no son libertades absolutas. Se admite en consecuencia la imposición de límites a su ejercicio siempre que a través de ellos no se elimine por completo el contenido de la misma.

Uno de estos límites es la facultad de intervención del Estado en la economía, que siendo la excepción, debe ser ejercida conforme a los fines que para el efecto se han marcado en la Constitución misma, esto es, con propósitos de equidad, igualdad, planificación, redistribución y solidaridad ${ }^{12}$. En otros términos, a través de su intervención se debe lograr un justo equilibrio entre las restricciones y el respeto de las libertades, esto es, entre la regulación y la libertad ${ }^{13}$. Como corolario de lo anterior, se afirma que nos encontramos ante un sistema de economía social de mercado que combina el ejercicio y protección de las libertades con la intervención del Estado.

En este orden, es preciso tener en cuenta que la libre competencia puede estar limitada por razones de interés general. De manera tal que las libertades privadas deberán ceder en la medida en que la restricción persiga un bien común.

Por último, hay que considerar que además de ser una libertad y un derecho, la libre competencia dentro del modelo social de mercado se reconoce como un deber. No basta por tanto que se garanticen las condiciones necesarias para su ejercicio, ni que se establezcan límites para su desarrollo, además resulta forzoso que se imponga su respeto y acatamiento como obligación a quienes participan en el mercado.

En conclusión las normas de libre competencia tienen una doble faceta. Una de carácter individual y otra de orden social o colectivo o, dicho en otros términos, cumplen sus funciones en dos ámbitos, el individual y el social ${ }^{14}$.

11 Véase en este sentido Ley 155 de 1959, Decreto 2153 de 1992, Ley 1340 de 2009.

12 Parejo Alfonso, Luciano. El nuevo sistema de defensa de la competencia. Algunas cuestiones generales sobre su fundamento constitucional y su organización específica en una administración independiente. Parejo Alfonso, Luciano y Palomar Olmeda, Alberto., Derecho de la competencia. Estudios sobre la Ley 15/2007, de 3 de julio, de Defensa de la Competencia, Madrid: La Ley, 2008, pp. 55; Alonso Soto, Ricardo. El interés público en la defensa de la competencia. Martínez Lage, Santiago y Petitbó Juan, Amadeo (Dirs.), La modernización del Derecho de la Competencia en España y la Unión Europea, Madrid: Marcial Pons, 2005, p. 33

13 Parejo Alfonso, Luciano, op. cit., pp. 70-71: "De esta suerte se compatibiliza la intervención del Estado (cabalmente mediante las técnicas reconducibles a la regulación) y el juego de la iniciativa privada en régimen de libe competencia en el mercado. La necesidad de esta compatibilización, una muestra más de la complementariedad estructural de Estado y mercado, trae causa de la inexistencia práctica del mercado perfecto como consecuencia de los fallos que el funcionamiento real de los mercados normalmente lleva consigo (...)".

14 Uría Fernández, Francisco. Las consecuencias jurídico-privadas de las conductas contraria a la ley de defensa de la competencia, Aportaciones de la Ley 52/1999, de 28 de diciembre, de reforma de la ley de defensa de la competencia. AdC, 1999, p. 173 “(...) no puede 
Estos dos planos de acción significan que las normas antitrust protegen tanto al individuo como a la comunidad y que cualquiera de ellos puede reclamar su aplicación.

En el ámbito individual la libre competencia es manifestación de una libertad individual que se atribuye a cada sujeto bajo la forma de derecho-deber. En este contexto su protección resulta indispensable para garantizar que los particulares pueden hacer uso de su autonomía privada y de su libertad contractual y, en esta medida, que existan las bases necesarias para que los empresarios compitan.

Desde la perspectiva social o colectiva la libre competencia debe protegerse para garantizar el adecuado funcionamiento del mercado y permitir el logro y la trasmisión de los beneficios que para la colectividad se derivan de dicho funcionamiento concurrencial.

A partir de las bases anteriores, se considera que deben prohibirse y sancionarse las conductas a través de las que se falsea, restringe, elimina o altera la libre competencia, pues a través de ellas se lesionan los derechos de los particulares y se eliminan además las ventajas de las que podría disfrutar la colectividad $^{15}$.

\section{LA PROHICIÓN DE LAS CONDUCTAS RESTRICTIVAS DE LA COMPETENCIA}

Y EL SISTEMA DE EXENCIONES

\subsection{La prohibición general}

El derecho antimonopolio prohíbe las conductas que tienen por objeto o como efecto restringir, falsear o alterar la libre competencia en un mercado

negarse que en la defensa de la competencia concurren tanto intereses públicos como privados de una forma probablemente inseparable lo que pone un juego viejas y nuevas formas de actuación de los poderes públicos". Las funciones que surten las normas antitrust en cada uno de estos planos excede el objeto de este estudio Reconocemos en todo caso la importancia que reviste el tema para identificar la incidencia de esta normativa y de sus beneficios en los dos planos señalados. Sobre las funciones del Derecho antitrust puede verse, entre muchos otros, Fikentscher, Wolfgang. Las tres funciones del control de la economía (Derecho Antimonopolio). Revista de Derecho Mercantil, Nos. 172-173, 1984, pp. 459 a 486; Robles Martín- Laborda Antonio. Libre competencia y competencia desleal, Madrid: La Ley, 2001, 1ª Ed. p. 45; Calvo Caravaca, Alfonso-Luis y Fernández de la Gándara, Luis, Política y Derecho de la Competencia, op. cit., pp. 3380-3381; Calvo Caravaca, Alfonso-Luis y Férnandez de la Gándara, Luis. Reflexiones en torno al concepto y funciones del derecho de la competencia. Boletín de la Gaceta Jurídica de la CE y de la Competencia, B- 85, 1993, pp. 13-22; Pascual y Vicente, Julio. Fundamentos y limitaciones de la defensa pública de la competencia. Gaceta Jurídica de la Unión Europea y la Competencia, marzo-abril, No 224, 2003, p. 13.

15 Sobre la necesaria preservación de los beneficios derivados de la libre competencia pueden verse entre muchos otros: Eizaguirre, José María, op. cit., p. 330; Fikentscher, Wolfgang, op. cit., pp. 459 a 486; y Díez Estella, Fernando. Los objetivos del derecho antitrust. Gaceta Jurídica de la Unión Europea y la Competencia, No. 224, 2003, pp. 32 a 52

Revist@e-Mercatoria, vol. 15 N.o1, ENeRo-Junio/2016,PP. 3-48 
determinado. Dentro de las conductas prohibidas se encuentran los acuerdos restrictivos de la competencia en sus distintas modalidades así el abuso de la posición de dominio y la regulación o notificación previa a la autoridad de competencia de las operaciones de concentración empresarial ${ }^{16}$.

A efectos de lograr sus fines, el ordenamiento de libre competencia acoge un modelo regulatorio que parte de la consagración una prohibición general que se acompaña y complementa con un régimen o sistema de excepciones. Generalmente el régimen de excepción sólo tiene alcance respecto de las conductas en las que participan dos o más empresas, siempre que además se logre demostrar que el acuerdo, decisión, recomendación o práctica concertada genera mayores beneficios que daños al mercado y a sus operadores (sistema del balance concurrencial $)^{17}$.

Europa sigue el modelo de prohibición-excepción al establecer en los artículos 101 y 102 del TFUE la prohibición general de las conductas restrictivas de la competencia (cárteles) y del abuso de la posición de dominio respectivamente; así como al consagrar un sistema de excepción legal o automática que puede operar de forma singular o a través de las denominadas exenciones por bloque o categorías.

Así pues, a efectos de que una conducta resulte prohibida y sancionada bajo la perspectiva del derecho antimonopolio en Europa es necesario constatar que además de encajar en la prohibición general (artículos 101.1 y 102 del TFUE) la misma no se encuentre excluida o excepcionada.

Conforme a lo anterior resulta esencial al adecuado funcionamiento del modelo de prohibición-exención entender las razones por las cuales las conductas que caen dentro de la prohibición bajo determinados supuestos pueden resultar legítimas, autorizadas y desarrollarse dentro del mercado sin objeciones, todo ello con el fin de comprender por qué razones se ha creado dentro del régimen de excepciones un amparo o protección para los acuerdos que generen beneficios desde la perspectiva ambiental.

\subsection{Sistema de Exencion Legal y Autoexamen}

En el Derecho Europeo de la Competencia hasta antes del Reglamento $1 / 2003^{18}$ las empresas que querían sustraer un acuerdo o convenio restrictivo de la libre

16 En el ordenamiento Colombiano, adicional a las anteriores conductas también se consideran prohibidos los denominados actos anticompetitivos (Ver artículo 48 del Decreto 2153 de 1992).

17 En la mayoría de ordenamientos el sistema de excepción no opera en los casos de Abuso de la Posición de Dominio.

18 Reglamento (CE) Num. 1/2003 del Consejo, de 16 de diciembre de 2002, relativo a la aplicación de las normas sobre competencia previstas en los artículos 81 y 82 del Tratado CE. (En adelanta Reglamento 1/2003). 
competencia, del conocimiento de las autoridades debía obtener una autorización previa y expresa de la Comisión siempre que no existiera un Reglamento de Exención para el sector económico.

El Reglamento 1/2003 modificó de manera radical la aplicación de la prohibición general de las conductas restrictivas (artículo 101 del TFU) y del sistema de excepción ${ }^{19}$.

En efecto, el Reglamento eliminó la competencia exclusiva de la Comisión para aplicar el apartado 3 del art. 101 del TFUE (antiguo artículo 81.3 del $\mathrm{TCE})^{20}$ y con ello las autorizaciones de carácter singular; en su lugar, estableció un sistema de excepción legal conforme al cual se consideran lícitas las conductas que a pesar de encajar en la prohibición del artículo 101.1 del TFUE cumplen con las exigencias del apartado 3 de dicho artículo ${ }^{21}$; sensu contrario, se consideran ilícitos aquellos acuerdos que estando comprendidos dentro de la prohibición (art. 101.1 del TFUE) no cumplen alguno de los requisitos del art. 101.3 del TFUE ${ }^{22}$ :

19 Aunque el Reglamento se refiere a los artículos 81 y 82 del Tratado CE haremos referencia a los artículos 101 y 102 del TFUE por ser esta la numeración actualmente vigente.

20 Beneyto Pérez, José María (Director) y Maillo González Orus, Jerónimo. Tratado de Derecho de la Competencia, Tomo I, Madrid: Bosch, 2005, p. LXVIII "Se ha producido la desmonopolización de la aplicación del art. 81.3 por la Comisión Europea, al pasar de un sistema de prohibición de los acuerdos restrictivos y de autorización previa a un sistema en el que son las autoridades y los jueces nacionales quienes deberán aplicar el artículo 81 de forma unitaria, a partir de la ponderación ex ante de los aspectos anti y procompetitivos de los acuerdos que deberán realizar los operadores económicos y sus asesores".

21 Vid. Beneyto Pérez, José María (Director) y Maillo González Orus, Jerónimo, Tratado de Derecho de la Competencia, Madrid: Bosch, Tomo I, 2005, p. LXIX, Rincón García Loygorri. Alfonso, Las conductas prohibidas. Beneyto, José María y Maillo, Jerónimo (Dirs), La nueva ley de defensa de la competencia. Análisis y comentarios. Barcelona: Bosch, 2009, pp. 179 y ss. Illescas, Rafael. El campo de aplicación del Derecho de la Competencia. Los instrumentos jurídicos de aplicación. Beneyto, José María y Maillo González Orus, Jerónimo (Dirs.), Tratado de derecho de la competencia Unión europea y España, Tomo I, Madrid: Bosch, 2005, pp. 160 y 161; Ortiz Blanco, Luís y León Jiménez, Rosario, Aplicación de las normas de defensa de la competencia a las grandes superficies de distribución minorista", Revista de Derecho, [en línea], VLEX - TR331, [Citada 15 de enero de 2014], http://www.vlex.com, p. 3"(...) por su parte. Las empresas sin necesidad de notificar el acuerdo a la Comisión, podrán valorar por sí mismas si un acuerdo cumple con los requisitos del artículo 81.3; si este fuera el caso, el acuerdo será válido desde el primer momento, sin necesidad de obtener una autorización por parte de la Comisión".

22 Ver considerando No. 4, y arts. 1 y 2 del Reglamento 1/2003. Además puede verse la Comunicación sobre las Cartas de Orientación, que refiriéndose al Reglamento 1/ 2003 establece en su parágrafo 1:"(...) el Reglamento también brinda seguridad jurídica al prever que los acuerdos que entran en el ámbito de aplicación del apartado 1 del artículo 81 pero cumplen las condiciones del apartado 3 de dicho artículo son válidos y plenamente ejecutables ab initio sin que sea necesaria una decisión previa de una autoridad de competencia (...)". Igualmente sobre el nuevo sistema de exención legal véase García Cachafeiro, Fernando, El Giro Norteamericano del Derecho Antitrust comunitario: El artículo 81 del Tratado CE y el artículo 1 de la Sherman Act, Revista de 
Al respecto indica el artículo 1 del Reglamento 1 de 2003 lo siguiente:

\section{"Artículo 1. Aplicación de los artículos 81 y 82 del Tratado}

1. Los acuerdos, decisiones y prácticas concertadas contemplados en el apartado 1 del artículo 81 del Tratado que no cumplan las condiciones del apartado 3 de dicho artículo están prohibidos, sin que sea necesaria decisión previa alguna a tal efecto.

2. Los acuerdos, decisiones y prácticas concertadas contemplados en el apartado 1 del artículo 81 del Tratado que reúnan las condiciones del apartado 3 de dicho artículo no están prohibidos, sin que sea necesaria decisión previa alguna a tal efecto.

3. La explotación abusiva de una posición dominante contemplada en el artículo 82 del Tratado está prohibida, sin que sea necesaria decisión previa alguna a tal efecto".

Bajo el nuevo sistema de excepción legal corresponde a cada empresa o cada operador económico examinar si su conducta (acuerdo) cumple con las condiciones establecidas en el apartado 3 del artículo 101.3 del TFUE.

Así pues, particulares y autoridades tendrán que verificar si la conducta en cuestión cumple los siguientes elementos:

1. Produce mejoras en la producción o distribución o contribuye a fomentar el progreso técnico o económico;

2. Permite que los consumidores o usuarios puedan participar de las ventajas generadas por el acuerdo.

3. Que las restricciones que genera son indispensables para obtener los beneficios y ventajas que persiguen las partes $y$,

4. Que las restricciones que derivan del acuerdo no otorgan a las partes la posibilidad de eliminar la competencia respecto a una parte sustancial de los productos o servicios contemplados.

El efecto más importante del sistema de excepción legal y del autoexamen es que las partes del acuerdo una vez que valoran que el mismo cumple con las condiciones establecidas en el apartado 3 del artículo 101 del TFUE pueden ejecutarlo sin necesidad de obtener un permiso o autorización previa de la Comisión Europea o de la Autoridad Nacional de Competencia ${ }^{23}$.

Derecho Mercantil, No. 255, 2005. p. 629 y De Eizaguirre, José María, op. cit., pp 360 a 364, 378 a 380 .

23 De esta opinión Alonso Soto, Ricardo, "Derecho de la Competencia", Menéndez, Aurelio (Dir.), Lecciones de Derecho Mercantil., Madrid: Thomson Civitas, 2007, 5a Ed., p. 235. También parece seguir esta línea de pensamiento Pace, Lorenzo Federico, Derecho Europeo de la Competencia. Probibiciones antitrust, control de concentraciones y procedimientos de aplicación, MadridBarcelona: Marcial Pons, 2007, p. 105 que considera: "El artículo 81, apartado 3, TCE regula una excepción a la prohibición del art. 81 apartado 1, TCE. En concreto, dispone que la probibición del apartado 1 podrá declararse inaplicable en caso de acuerdos que contribuyan a mejorar la 
Para garantizar que el proceso de autoevaluación no es arbitrario y brindar apoyo a los particulares que deben hacer el autoexamen y a las autoridades que deben revisar dicho examen se ha dispuesto que deberán tener en consideración además de los Reglamentos de Exención por Categoría, las Directrices sobre la aplicación del apartado 3 del artículo 81 del Tratado, particularmente los numerales 38 a $116^{24}$, las directrices sobre las diferentes clases de acuerdos (horizontales y verticales), las Comunicaciones que orientan la aplicación de las normas comunitarias y, por supuesto, la jurisprudencia comunitaria.

Excepcionalmente, si se trata de una situación novedosa en relación con la cual los instrumentos que hemos indicados no son útiles o simplemente resultan insuficientes, la Comisión puede emitir una carta de orientación siempre que ello sea compatible con sus prioridades ${ }^{25}$.

\subsection{El sistema de exención legal a través de los reglamentos de exencion por categoría}

Adicional al sistema de excepción legal que tiene lugar a través del autoexamen, el Derecho Europeo de la Competencia contempla que también se encuentran exceptuados de la aplicación del régimen de sanciones los acuerdos restrictivos que estando dentro la prohibición general del artículo 101.1 del TFUE se encuentran amparados por un Reglamento comunitario de Exención por Categoría.

Como su nombre lo indica, estos Reglamentos permiten la exención en bloque de sectores económicos o de una categoría de acuerdos que a nivel comunitario se consideran dignos de una protección especial. Dicha protección se debe a la necesidad de que los acuerdos se ejecuten a pesar de ser estos restrictivos de la competencia o a las especiales características del sector que implican que se adecuado funcionamiento solo pueda tener lugar siempre que se permitan acuerdos restrictivos de la competencia.

producción o la distribución de los producto o a fomentar el progreso técnico o económico" (La negrita es nuestra).

24 Una guía sobre el análisis y el alcance de cada uno de estos requisitos, se encuentra dispuesto en la Comunicación de la Comisión, de 27 de abril de 2004, Directrices sobre la aplicación del apartado 3 del artículo 81 del Tratado" (2004/ C 101/08), DOCE del 27.4.2004

25 Comunicación de la Comisión de 27 de abril de 2004, relativa a las orientaciones informales sobre cuestiones nuevas relacionadas con los artículos 81 y 82 del Tratado CE que surjan en asuntos concretos. 6 a 25. Las cartas de orientación constituyen un mecanismo excepcional que de ninguna forma sustituye a las autorizaciones individuales (Punto II.7), y cuya finalidad no es otra que la de facilitar a los particulares la evaluación de sus acuerdos a la luz de las disposiciones de libre competencia, sin prejuzgar ni impedir la evaluación que de una conducta pueden realizar los tribunales comunitarios (Punto VI.25) 
Dentro de la normativa comunitaria dichos Reglamentos de Exención generalmente se acompañan de unas directrices comunitarias que sirven para interpretar los términos de la exención, para facilitar a los operadores económicos las normas y reglas impuestas por el Reglamento y que orientan a los jueces y autoridades de competencia en cuanto al ámbito de protección, a fin de saber si las conductas restrictivas están exentas y libres de sanción o, por el contrario pueden sancionarse en los términos previstos en el derecho comunitario y del derecho nacional.

Las exenciones en bloque pueden ser revocadas por la Comisión Europea cuando el acuerdo deje de cumplir cualquiera de los requisitos previstos en el art. 101.3 del TFUE y/o alguno de los supuestos particulares establecidos en el específico Reglamento. En estos casos corresponde a la Comisión la carga de probar el motivo de la revocación y ésta sólo surte efectos ex nunc, de manera que aquellas conductas realizadas estando vigente la autorización se consideraban lícitas y válidas ${ }^{26}$.

\section{LA PROTECCIÓN DEL MEDIO AMBIENTE COMO FIN DEL DERECHO DE LA LIBRE COMPETENCIA}

Según viene de decirse, dentro del modelo de economía social de mercado la libre competencia económica se encuentra al servicio de los fines o intereses comunes. En este sentido, las normas de libre competencia vienen reconociendo que su aplicación no sólo pretender el bienestar de los empresarios sino el de los consumidores así como el adecuado funcionamiento del mercado en general.

Bajo esta perspectiva no bastan las eficiencias económicas (trasladadas o no al consumidor) sino que es necesario considerar además las eficiencias sociales a efectos de conceder la aplicación de un régimen de excepción. Precisamente por ello no se concibe ni se justifica una libre competencia que genere beneficios económicos pero que lesione el derecho a un medio ambiente sano incluso si esto se revierte en menores costos para los empresarios y los consumidores ${ }^{27}$.

Sobre este particular los avances del Derecho Europeo de la Competencia marcan un derrotero en cuanto a la importancia de lograr una convivencia y

26 De conformidad con el art. 29.1 del Reglamento $1 / 2003$, la facultad para retirar el beneficio de la autorización le corresponde a la Comisión y a las autoridades nacionales, en estos casos corre a cargo de ellas probar que el acuerdo no reúne todas las condiciones previstas en el art. 81.3 del TCE o que incumple algunos de los requisitos particulares previstos en el Reglamento correspondiente.

27 Weitz, Nurit. Libre comercio vs. Protección Ambiental; Un debate para suramerica.South americabusiness fórum, [en línea] 2011 [citado el 8 de octubre de 2014] http://www.sabf. org.ar/assets/files/essays/Libre\%20comercio\%20vs\%20Proteccion\%20ambiental2.pdf "La expansión del comercio internacional, basado en las fuerzas del mercado y en la libre competencia, ba originado intensas críticas por parte de las organizaciones ambientales no gubernamentales. Perciben que la globalización tiende a minar leyes nacionales y acuerdos internacionales sobre protección del medio ambiente". 
un desarrollo armonioso de la protección al medio ambiente y el ejercicio y crecimiento de la actividad empresarial.

Con este fin resulta necesario ilustrar a continuación y a grandes rasgos los principios y objetivos de la política de protección al medio ambiente y las normas que ordenan un funcionamiento integral de dichas políticas con otras normativas comunitarias principalmente de orden empresarial y económico:

En el contexto Europeo se evidencia un constante desarrollo normativo en el ámbito de la protección al medio ambiente. Es tanto así, que la doctrina internacional ha logrado identificar seis periodos distintos a través de los cuales se han consolidado las normas y principios reinantes en esta materia a hoy día ${ }^{28}$.

Resultado de este proceso evolutivo es el artículo 191 del Tratado de Funcionamiento de la Unión Europea -TFUE- (antiguo artículo 174 del Tratado $\mathrm{CE}$ ), que establece de forma general los objetivos y principios de la política comunitaria en el ámbito del medio ambiente.

Como primer objetivo se indica que será labor de la Unión Europea la conservación, protección y mejora de la calidad del medio ambiente ${ }^{29}$.

Adicionalmente la norma comunitaria establece que la política ambiental debe propender por la salvaguarda de la salud de las personas, la utilización prudente y racional de los recursos naturales, entendida esta última como el derecho a explotar los recursos propios con una limitante del uso razonable de ellos, lo cual se ha interpretado como la obligación de los Estados de reducir o eliminar los patrones de producción y consumo insostenibles ${ }^{30}$.

El último y más transversal objetivo que debe perseguir la Unión Europea es el fomento de medidas a escala internacional destinadas a hacer frente a los problemas regionales o mundiales del medio ambiente, en particular, aquellas en contra del cambio climático ${ }^{31}$.

El numeral segundo del artículo 191 del TFUE expresa los principios en los que debe basarse la política de protección del medio ambiente así: El principio de protección elevada, de cautela ${ }^{32}$, de acción preventiva ${ }^{33}$ y de corrección

28 Vedder, Hans H.B. y Jans Jan H, European Enviromental Law, Amsterdam: Europa Law Publishing, 2008, p. 3.

29 Como quiera que el objetivo es suficiente amplio y flexible, es posible adaptar la norma a nuevas situaciones que puedan demandar cualquier tipo de protección. Ver Ibidem p. 26.

30 Principle 9 of The Rio Declaration.

31 Esta norma habilita a los Estados Miembros a adoptar de medidas cuyos efectos sean extraterritoriales, siempre y cuando este ejercicio se presente sin vulneración de normas internacionales.

32 Vedder, Hans H.B. y Jans Jan H, op. cit. p. 37 This means that, if there is a strong suspicion that a certain activity may bave environmentally barmful consequences, it is better to act before it is too later rather tan wait until full scientific evidence is available which incontrovertibly shows the causal connection. Ibídem op. cit, p. 41 . The prevention principle allows action to be taken to protect the environment at 
de los atentados al medio ambiente ${ }^{34}$ todos los cuales se establecen como estandartes de la política ambiental complementados con el conocido como the polluter pays principle ${ }^{35}$, del cual emana la obligación del agente económico que contamina de pagar una suma determinada de dinero, por el simple hecho de generar un acto contaminante, castigable o no por la ley.

De conformidad con el artículo 11 del TFUE las normas y principios tendientes a la protección del medio ambiente deben integrarse con las demás políticas económicas de la Unión Europea generando una amalgama jurídica cuya consecuencia inmediata y necesaria sea la generación de un escenario de desarrollo sostenible de la Comunidad ${ }^{36}$.

En esta misma dirección de integración y consolidación e interrelación de políticas, el VI Programa de Acción de la Comunidad Europea de Medio Ambiente en varios de sus apartes presenta de manera evidente y precisa mandatos tendientes a la integración de los intereses de las empresas, los consumidores, el mercado y el medio ambiente. Este programa implica que las políticas ambientales no se presentan como un fin en sí mismo de manera que se invita a trabajar con el mercado a través de los intereses de empresa y consumidores en la búsqueda de una producción y modelos de consumo más sostenibles ${ }^{37}$.

Conforme lo reconocen las Instituciones Europeas y, particularmente, la Comisión, la protección del medio ambiente no implica de suyo limitar el crecimiento o el consumo; por el contrario, los estándares medioambientales deben impulsar la innovación y esta a su vez crea nuevos mercados y espacios para la entrada de nuevos competidores. Una competencia más agresiva pero construida a partir de estándares ambientales más altos termina generando ventajas para todos los actores del mercado y para el bienestar de la colectividad.

Este Programa ha implicado un cambio de paradigma en cuanto invita a la búsqueda de mecanismos alternativos al derecho sancionador como vehículos de protección del medio ambiente, ya sea mediante la introducción de elementos que recompensen los buenos resultados de los agentes económicos en el desarrollo de su proceso elaboración y producción, o mediante la trans-

an early stage. It is no longer primarily a question of repairing damagae after it has occurred. Instead the principle calls for measures to be taken to prevent damage occurring at all.

34 Vedder, Hans H.B. y Jans Jan H, op. cit p, 42. European policy on the environment shall be based on the principle that enviromental damage should as a priority be rectified at its source. According to the source principle, damaga to the environmente should preferably not to be prevented by using ed-of-pipe technology. Vedder, Hans H.B. y Jans Jan H, op. cit. p. 44 This programme is base don the principle that charging polluters the costs of accion to combat the pollution they cause will encourage them to reduce that pollution and endeavour to fin less polluting products or technologies.

37 Ver más sobre esto en la Comunicación de la Comisión al Consejo y al Parlamento Europeo, al Comité Económico y Social y al Comité de las Regiones sobre el Sexto Programa de Acción de la Comunidad Europea en materia de Medio Ambiente. COM (2001) 31 final 24.1.2001 
misión de información a los consumidores que les permitan tomar decisiones de compra influenciadas en el componente ambiental de los productos y servicios que adquieren.

Se ha pasado del derecho sancionador y de una regulación completamente estricta e imperativa a la implementación de mecanismos que promueven una actitud distinta de los empresarios y de las consumidores en cuanto a la protección del medio ambiente. En esta ruta se ha logrado la consolidación de mecanismos que avalan los acuerdos restrictivos de la libre competencia siempre que tales acuerdo entre agentes económicos pretendan la generación de mejores resultados desde la perspectiva del medio ambiente ${ }^{38}$.

Un sector importante de la doctrina europea entre los que caben destacar autores como SUZANNE JOY, JAN JANS y HANS VEDDE ${ }^{39}$, evidencian en sus trabajos una clara tendencia de internalizar los fines de protección del medio ambiente dentro de la política de competencia. En otros términos, el medio ambiente y la garantía de este derecho a los ciudadanos no se establece como un mecanismo de limitación del mercado, sino como un fin intrínseco de las políticas económicas. La libre competencia, encuentra como componente adicional a la eficiencia económica y la protección al consumidor, la salvaguarda de un ambiente sano y la generación de un desarrollo sostenible.

Para materializar esta sinergia entre la libertad de competencia y la protección del medio ambiente se propone, entre otros, los siguientes instrumentos:

i. Lograr que los costos medioambientales sean asumidos como propios por el empresario y que el proceso de competencia tenga lugar en cuanto a los estándares medio ambientales que deben cumplir los productos, lo cual daría como resultado el mejoramiento de sectores industriales ya existentes y el surgimiento de nuevos;

ii. Una adecuada implementación del principio conforme al cual el agente contaminador paga $i_{i}$ implementación que debería tener lugar en el sentido de generar una mayor competencia a través de los costos medio ambientales, siempre y cuando

38 Directrices sobre la aplicabilidad del artículo 101 del Tratado de Funcionamiento de la Unión Europea a los acuerdos de cooperación horizontal (Texto pertinente a efectos del EEE) 2011/C 11/01. Las presentes Directrices no contienen un capítulo separado referente a los acuerdos sobre medio ambiente como ocurría en las Directrices Horizontales de 2001. La determinación de los estándares, que era el objeto principal del antiguo capítulo relativo a los acuerdos sobre medio ambiente, se contempla con mayor propiedad en el capítulo de las presentes Directrices referente a la estandarización. Por lo general, en función de los problemas de competencia que planteen los acuerdos sobre medio ambiente, se deberán evaluar con arreglo al capítulo pertinente de las presentes Directrices, a saber, el relativo a los acuerdos de I+D, de producción, de comercialización o de estandarización.

39 Vedder, HANS H.B. Voluntary Agreements and Competition Law. Fondazione Eni Enrico Mattei. [en línea] [citado el 20 noviembre de 2014] http://www.feem.it/userfiles/attach/ Publication/NDL2000/NDL2000-079.pdf 
estos costos no sean reflejados en los consumidores finales sino que sean asumidos por los actores económicos, ya sea en el nivel de producción o de intermediación ${ }^{40}$. iii. Crear una cultura de consumo que privilegie los productos y los servicios que son el resultado de procesos ambientalmente idóneos.

iv. Beneficios desde el punto de vista de la aplicación de un sistema de excepción.

La realización de estas metas se haría efectiva en la práctica a través del desarrollo y celebración de acuerdos voluntarios entre los agentes económicos toda vez que son éstos quienes se encuentran familiarizados con las particularidades que el proceso de producción demanda y tienen mayor capacidad de decisión por su nivel de experticia que aquella con la que cuenta las autoridades públicas.

Esta amalgama entre libre competencia y medio ambiente que se erige en la Unión Europea como una nueva tendencia y que según explicaremos se materializa en la regulación de los acuerdos horizontales que teniendo efectos restrictivos generan ventajas en la protección del medio ambiente, no es extraña al ordenamiento jurídico colombiano ni mucho menos ajena al modelo de economía social de mercado establecido en nuestra Constitución Política ni tampoco a nuestras norma antimonopolio.

En efecto, a la libertad de competencia se le ha dotado de un contenido social que se ve claramente plasmado en el artículo 333 de nuestra Carta Política. Precisamente en el último inciso de la norma en mención se plasma la obligación de la ley de generar una congruencia entre la libertad económica y el medio ambiente a lo cual haremos referencia en la IV parte de este escrito.

\section{LOS ACUERDOS VOLUNTARIOS SOBRE LA PROTECCIÓN DEL MEDIO AMBIENTE Y SU REGULACIÓN DESDE LA PERSPECTIVA DE LA LIBRE COMPETENCIA}

Por regla general la protección del medio ambiente se encuentra establecida en normas de orden constitucional y legal. El Estado en ejercicio de su potestad reguladora y de su poder de intervención en la economía, establece a través de normas de carácter imperativo una serie de deberes y de condiciones que deben cumplirse para el ejercicio de las actividades económicas y el desarro-

40 En esta vía se reevalúa y se le dota de otro contenido al principio the polluter pays, ya que la implementación del mismo trae como consecuencia inmediata el aumento de costos de ejercer determinada actividad económica y al mismo tiempo aumenta el riesgo que actores ilegalmente evadan el cumplimiento de esta carga impositiva. Mediante la interiorización de los costos, es decir, incluyendo estos en el proceso de producción, se podría lograr una maximización de los recursos (maximización en términos económicos y ambientales), logrando una ganancia tanto ambiental como económica. Fin que se logra, a través de los acuerdos voluntarios. 
llo de la actividad empresarial ${ }^{41}$. Bajo esta perspectiva el derecho a un medio ambiente sano y a la protección del mismo constituyen un límite al derecho a la libre competencia económica.

Esta perspectiva tradicional que ve en la protección del medio ambiente y de la competencia económica dos extremos o polos opuestos en los que la actividad empresarial debe siempre ceder en pro del interés general, ha venido siendo superada, tal y como lo indicamos al inicio de este artículo. El cambio no ha significado un orden de privilegios, esto es, que per se se tengan que privilegiar la libertad económica en detrimento del medio ambiente. El cambio y la reorientación ha implicado la necesidad de lograr -a través de distintos instrumentos- que las empresas decidan competir dentro de los mercados incorporando en sus estados financieros costos de una producción y comercialización que resulte ambientalmente menos lesiva y óptima.

Bajo esta nueva perspectiva, son los empresarios los que en ejercicio de su autonomía privada deciden competir en el mercado bajo estándares mucho más estrictos de protección al medio ambiente. También el consumidor se vuelve protagonista de este nuevo modelo, en la medida en que selecciona o escoge su proveedor a partir del cumplimiento que este ofrece de las normas de protección ambiental, de salud, de seguridad y de protección laboral ${ }^{42}$.

En este contexto surgen los denominados Acuerdos Voluntarios de Cumplimiento Ambienta ${ }^{43}$ como mecanismos o herramientas que son adoptadas libremente por los agentes económicos con miras a garantizar la protección

41 Consejo Nacional de Producción Limpia. Acuerdos de Producción Limpia [en línea], 2005 [Citado 2 de abril de 2015] http://www.cpl.cl/, p. 7 "En materia de protección ambiental existen boy en día diversas berramientas de gestión pública que pueden aplicar los Estados para influir en determinados comportamientos de los actores productivos. Entre ellas pueden distinguirse el comando y control (la regulación tradicional), los instrumentos económicos (directos e indirectos) y las iniciativas voluntarias (...) las iniciativas voluntarias se vinculan a la necesidad de disponer de instrumentos complementarios a la regulación tradicional -berramienta de comando y control- o a los instrumentos de carácter económico, que permitan elevar el compromiso de las empresas con la gestión ambiental, incluso más allá de lo exigido por la normativa, lo que facilita la obtención de ganancias ambientales".

42 Comunicación (2002) 412 final. Comunicación de la Comisión al Parlamento Europeo, al Consejo, al Comité Económico y Social y al Comité de las Regiones. Acuerdos medioambientales a nivel Comunitario en el marco del plan de acción "Simplificar y mejorar el marco regulador", p. 5 citando la Comunicación de la Comisión COM (2001) 31 final de 24.1.2001. "Las fuentes de la contaminación ya no se concentran en instalaciones industriales aisladas sino que consisten en actividades económicas múltiples y tienen que ver con el comportamiento de los consumidores. Así queda muy limitado el margen para resolver estos problemas mediante un simple sistema de mando y control". Por consiguiente "en algunos casos será más adecuado recurrir a métodos distintos de la reglamentación y a medios flexibles de tratar las cuestiones de medio ambiente". Opciones distintas de la normativa tradicional como pueden ser los compromisos voluntarios, pueden ser también un medio de incitar a las empresas a innovar y a responder a los retos medioambientales".

43 Delmas, Magali A. Terlaak, Ana K. A Framework for analyzing environmental voluntary agreeents. Alifornia Law Reiew, 2001, vol. 43, p. 44. 
del medio ambiente y promover la libre competencia ${ }^{44}$. Se trata de acuerdos que generalmente constituyen una derivación de la Responsabilidad Social Empresarial (CSR por sus siglas en inglés) que se traduce en compromisos no legales, pero no por ello menos imperativos, a través de los cuales se promueve la ética y competencia a partir de la protección del medio ambiente ${ }^{45}$.

\section{Naturaleza y Beneficios de los acuerdos Voluntarios DE CUMPLIMIENTO AMBIENTAL}

Los acuerdos voluntarios han surgido e incrementado su popularidad entre los particulares como un complemento a la normativa protectora del medio ambiente ${ }^{46}$. Se instituyen como un mecanismo de internalización de los costos de producción y una verdadera compaginación entre la protección del medio ambiente y el ejercicio de la libre competencia.

La Comunicación sobre Acuerdos del Medio Ambiente de 2002 de la Comunidad Europea ${ }^{47}$, define por Acuerdo Voluntario o Acuerdos Medioambientales aquellos por medio de los cuales las partes se comprometen a lograr

44 Es importante indicar que la doctrina también se refiere bajo la expresión de acuerdos voluntarios de cumplimiento ambiental a los acuerdos que son celebrados entre gremios o empresarios con las autoridades ambientales. A efectos de nuestro estudio estos acuerdos no serán relevantes desde la perspectiva del derecho de la libre competencia como quiera que ellos son resultado de la intervención del Estado en la economía y no consecuencia de la gestión del Estado como operador económico. Sobre la clasificación de los instrumentos e iniciativas de carácter voluntario puede verse Consejo Nacional de Producción Limpia. Acuerdos de Producción Limpia [en línea], 2005 [Citado 2 de abril de 2015] http://www. cpl.cl/, p. 8 y siguientes

45 La responsabilidad social de las empresas (RSE) es la integración voluntaria, por parte de las empresas, de las preocupaciones sociales y ambientales en sus operaciones empresariales $y$ sus relaciones con sus interlocutores. Hay empresas que deciden ir más allá de los requisitos jurídicos y obligaciones mínimos presentes en los convenios colectivos para abordar las necesidades de la sociedad. Mediante la RSE, empresas de todos los tamaños, en cooperación con sus interlocutores, pueden ayudar a conciliar las ambiciones económicas, sociales y ambientales. Así, la RSE se ba convertido en un concepto cada vez más importante, tanto en el mundo como dentro de la UE, y forma parte del debate en torno a la globalización, la competitividad y la sostenibilidad. En Europa, fomentar la RSE refleja la necesidad de defender valores comunes y aumentar el sentido de la solidaridad y la cobesión. Comunicación en RSE, "Poner en práctica la asociación para el crecimiento y el empleo: hacer de Europa un polo de excelencia de la RSE" COM (2006) 136 final.

46 OCDE. Voluntary Approaches for Environmental Policiy - an Assessment, 1999. OCDE. Voluntary Approaches for Environmental Policy Effectiveness, Efficiency and Usage in Policy Mixe, 2003. Disponibles en www.oecd.org. Ver también la Comunicación de la Comisión al Consejo y al Parlamento Europeo relativa a los acuerdos sobre medio ambiente COM (1996) 561 final de 27.11.1996.

47 Comunicación (2002) 412 final. Comunicación de la Comisión al Parlamento Europeo, al Consejo, al Comité Económico y Social y al Comité de las Regiones. Acuerdos medioambientales a nivel Comunitario en el marco del plan de acción "Simplificar y mejorar el marco regulador". 
una reducción de la contaminación conforme a la legislación medioambiental o a cumplir objetivos medioambientales enunciados en el artículo 174 del Tratado $\mathrm{CE}^{48}$.

A partir de esta definición la doctrina ha identificado dos tipos de acuerdos voluntarios: Los primeros considerados como verdaderas formas de autorregulación o acuerdos voluntarios propiamente dichos (acuerdos de caballeros) y, la segunda categoría, comúnmente desarrollada en Estados Unidos, que corresponden a los acuerdos para cuya celebración el legislador ha establecido las bases de la regulación, determinando los objetivos y los mecanismos de su implementación así como las eventuales sanciones para garantizar su cumplimiento. Esta segunda categoría se corresponde a una manifestación de corregulación entre gobierno y particulares, en el desarrollo de las obligaciones a cargo de estos últimos ${ }^{49}$.

En el ámbito Europeo la Comisión interviene en el ámbito de la autorregulación y de la corregulación. En primer lugar, la Comisión tiene dentro de sus competencias reconocer los acuerdos medioambientales una vez analizadas las observaciones remitidas por el Parlamento y el Consejo respecto de cada uno de ellos. En segundo lugar, la Comisión puede establecer los elementos claves sobre los objetivos y el seguimiento de los compromisos adquiridos, en el caso que los acuerdos medioambientales tengan lugar en un contexto de corregulación. En cualquiera de los supuestos anteriores la Comisión conserva su competencia para recurrir a su derecho de iniciativa y proponer la expedición de una legislación vinculante sobre los temas que abarcan los acuerdos voluntarios.

Tanto la doctrina como las Instituciones Europeas reconocen que los Acuerdos Medioambientales pueden generar un número plural de ventajas, entre otras las siguientes:

48 Actual artículo 191 del TFUE.

49 En el ámbito Europeo la Comunicación (2002) 412 final 17-7-2012 sobre Acuerdos medioambientales a nivel comunitario en el marco del Plan de acción "Simplificar y mejorar el marco regulador", ha admitido esta forma de regulación. Los acuerdos medioambientales pueden celebrarse también sobre la base de un acto legislativo, es decir, de una manera más vinculante y formal en el contexto de la regulación, lo cual permite a las partes implicadas aplicar una norma determinada de la legislación comunitaria. En ese marco regulador, el legislador determina los aspectos fundamentales de la legislación: los objetivos que deben alcanzarse, los plazos y mecanismos de puesta en práctica, los métodos para controlar su aplicación y las posibles sanciones a fin de garantizar la seguridad jurídica. La corregulación suele ser iniciada por la Comisión, bien por iniciativa propia bien en respuesta a una acción voluntaria por parte de la industria. La corregulación, pues, tiene las ventajas de los acuerdos medioambientales y las garantías jurídicas que proporciona un planteamiento legislativo. La Comisión propone al legislador que la corregulación se base en un acto legislativo. Por consiguiente, todas las propuestas sobre el tema considerado deben someterse al legislador". 
En primer lugar, dado que estos acuerdos encuentran cabida en ciertos ámbitos donde la regulación directa (aquella realizada mediante políticas legislativas o gobernativas) no tiene alcance, se constituyen en una extensión de las normas en ámbitos inalcanzables para las autoridades ${ }^{50}$.

En segundo lugar, estos acuerdos permiten que los actores del mercado, que son quienes conocen la relación costo-beneficio de la implementación de una política ambiental, establezcan el alcance de sus compromisos ${ }^{51}$.

Adicionalmente, partiendo de un actuar correcto de los agentes económicos, estos acuerdos tienen un tinte democrático, de manera que generan un mayor acceso a la información medio ambiental e incluso permiten la participación de número plural de sujetos, entre estos, los consumidores.

Finalmente, hay que señalar que estos acuerdos tienen un mayor alcance y cobertura en una economía actualmente globalizada y en la que resulta indispensable impactar la producción y comercialización masiva y no sólo las actuaciones de los operadores económicos individualmente considerados ${ }^{52}$.

En contraposición a las ventajas mencionadas también se plantean algunas críticas:

La primera y más obvia es que estos acuerdos como su nombre lo indican son voluntarios, y por ende, no son compulsorios, obligatorios para las partes que lo suscriben, de manera que no constituyen una garantía de la reducción de los riesgos medio ambientales ${ }^{53}$. Téngase en cuenta en todo caso, que los Acuerdos Medioambientales que sean consecuencia de un proceso de corregulación sí están sometidos a un esquema de seguimiento, de insistencia y de sanciones. Por lo que respecto de ellos, la crítica no resulta válida.

SEE HARMAN, "Enviromental Regulation in the 21st Century", Environmental Law Review, 2006, pp. 141- 149.

51 Téngase en cuenta que son los actores quienes van a la velocidad del mercado y son ellos los más idóneos y los que pueden reaccionar con mayor rapidez frente a los problemas medio-ambientales que pueden demandar de la empresa un proceso la adaptación y modificación en sus procesos productivos y de comercialización.

$52 \mathrm{Al}$ respecto puede analizarse el caso de los acuerdos voluntarios celebrados enbtre empresas de la Comunidad Autónoma de La Rioja en España. "La firma de acuerdos voluntarios con diferentes sectores industriales riojanos pretende establecer pactos de manera voluntaria con las industrias consiguiendo ayuda en la aplicación de la normativa ambiental y costes más reducidos para las empresas. Es más fácil cuando los sectores industriales se asocian y así, de forma conjunta, establecen sus propios mecanismos de gestión en la aplicación de la normativa ambientan y consiguen una simplificación de procedimientos, al ser tramitados en gran parte desde la asociación". Acuerdos de Producción Limpia: Gestión y Práctica [en línea], 2003 [Citado el: 10 de febrero de 2015] www.dialnet.unirioja.es.

53 Rehbinder. Environmental Agreements: A new instrument of environmental policy. European University Institute, Jean Monnet Chair Paper RSC. No. 97/45. A pesar que la doctrina ha considerado que estos pactos no poseen un medio coercitivo para lograr su cumplimiento, como todo acuerdo celebrado válidamente, se convierte en ley para las partes, de manera que las instituciones competentes pueden abrir un camino jurídico con miras a lograr la ejecución de las obligaciones contraídas ante el juez natural del contrato. 
En contraposición a la ventaja que los acuerdos pueden consolidarse como un camino democrático en el que se integran los diversos agentes del mercado, se endilga que estos pactos pueden constituir una forma de exclusión de ciertos participantes en las actividades comerciales. Y es en este sentido que se indica pueden constituir un elemento que facilita y a su vez disfraza o encubre actos de colusión entre diversos competidores y, en general, conductas anticompetitivas. En efecto, el establecimiento de condiciones particulares, entiéndase, estándares de altísima calidad para el ejercicio de una determinada actividad, puede constituir una barrera para la entrada de nuevos competidores en el nicho del mercado o bien un factor de exclusión para quienes participan en el mismo ${ }^{54}$.

Este efecto perverso sobre la libre competencia económica fue identificado por la Comisión Europea en la Comunicación (2002) 412 final sobre Acuerdos medioambientales cuando señaló los parámetros que deben cumplir dicho acuerdos para tener reconocimiento en el contexto de la Unión ${ }^{55}$ :

"Los acuerdos medio ambientales tienen que cumplir las disposiciones del Tratado CE relativas al mercado interior y las normas de competencia, incluidas las directrices sobre ayudas estatales para la protección del medio ambiente. Deben, por consiguiente, cumplir lo establecido en el artículo 81 del Tratado. (...)". (negrita fuera de texto).

 AMBIENTAL QUE TENGA POR OBJETO O COMO EFECTO RESTRINGIR LA LIBRE COMPETENCIA}

Tal como lo indicamos up supra el artículo 101.1 del TFUE determina los acuerdos, decisiones, recomendaciones y prácticas concertadas que atentan contra el ejercicio de la libre competencia económica. Así pues, en cuanto los acuerdos voluntarios de cumplimiento ambiental tengan por objeto o como efecto alterar o falsear la libre competencia, se convertirán en conductas

54 En el contexto internacional Weitz, Nurit. Op. cit, señala "Los acuerdos multilaterales sobre el medio ambiente (AMUNA) constituyen los instrumentos más sofisticados diseñados para la protección del medio ambiente. Sin embargo pueden llegar a transformarse en la nueva generación de barreras comerciales injustificadas que ciertos países desarrollados imponen sobre las economías más débiles (...). Los estándares ambientales por ciertos países desarrollados forman parte de la "nueva generación" de restricciones a la importación de bienes. La UE lidera esa tendencia y cuanta como principal aliado a reconocidas organizaciones ambientalistas"

55 También sobre este tema en las Directrices sobre acuerdos horizontales de 2001 se dispuso "192. La Comisión es favorable al recurso a acuerdos medioambientales como instrumento de realización de los objetivos establecidos en el artículo 2 y 174 del Tratado, así como en los programas de acción comunitarios en materia de medio ambiente, siempre y cuando tales acuerdos sean compatibles con las normas de competencia". 
reprochables y repudiadas por el derecho antimonopolio y, en consecuencia, serán objeto de sanción tanto desde la perspectiva administrativa como civil.

Con el fin de promover la celebración y el cumplimiento de los acuerdos voluntarios, incentivar el uso de este mecanismos y de que se ejecución resulte compatible con las normas de protección al mercado único, el legislador comunitario estableció desde el año 2001 la posibilidad de que los mencionados acuerdos, así como cualquier otro que tenga efectos restrictivos pero que persigan el cumplimiento de finalidades ambientales, puedan declararse exentos.

Conforme se indicó up supra bajo el sistema de excepción legal establecido en el Reglamento No. 1 de 2003 los acuerdos prohibidos pueden quedar exentos bien sea porque existe un Reglamento de Exención por Categoría que cobija las conductas en cuestión y las dota de legitimidad, o bien, porque de dichos acuerdos voluntarios a pesar de no estar amparados por un Reglamento, cumplen con las condiciones del apartado 3 el artículo 101 del TFUE esto es, se trata de acuerdos que contribuyen a mejorar la producción o la distribución de los productos o a fomentar el progreso técnico o económico, siempre que además y al mismo tiempo preserven a los usuarios una participación equitativa en el beneficio resultante de los mismos sin eliminar la competencia de forma absoluta.

En otros términos, la Unión Europea con el fin de compatibilizar el leal y libre ejercicio de la libre competencia económica con los fines de protección al medio ambiente, ha optado por amparar los acuerdo restrictivos de la competencia que buscan o persiguen mejoras en la protección del medio ambiente, dentro de los cuales la categoría más importante son los acuerdos voluntarios de protección medioambiental en los términos ya explicados.

A efectos de materializar dicha compatibilización la Unión Europea decidió amparar los acuerdos voluntarios al considerar que la finalidad de los mismos compensa con creces los efectos negativos que frente a los competidores y al mercado podían derivar de ellos. Es decir, que aplicado un test de balance concurrrencial la conclusión de la autoridad comunitaria era que los beneficios derivados del acuerdo y sus efectos positivos superaban las consecuencias adversas derivadas de la reducción u obstaculización de la competencia.

No obstante lo anterior, es preciso tener en cuenta que los acuerdos medioambientales no se han regulado nunca a través de un Reglamento de Exención lo que impone concluir que se deja a las empresas el deber de cumplir las condiciones del apartado 3 del artículo 101 del TFUE a efectos de obtener la exención respectiva.

Así las cosas, la protección brindada por el ordenamiento europeo se ha limitado a la regulación de dichos acuerdos en las Comunicaciones de la Comisión contentivas de las Directrices para el análisis de los acuerdos restrictivos de carácter horizontal.

En efecto, inicialmente la regulación se estableció de forma expresa en las directrices que sobre acuerdos horizontales se publicaron en el año 2001 y 
que acompañaban los Reglamentos (CE) 2658/2000 de exención a los acuerdos de especialización y (CE) 2659/2000 de exención a los acuerdos de investigación y desarrollo. Posteriormente, dicha protección quedó subsumida en las Directrices de 2011 específicamente dentro de las regulaciones de los acuerdos de producción, comercialización y de estandarización conforme se explica a continuación.

\section{Directrices Sobre la aplicabilidad del artículo 81 Del tratado CE A LOS ACUERDOS DE COOPERACIÓN HORIZONTAL ${ }^{56}$}

Las Directrices sobre Acuerdos Horizontales publicadas en el año 2001 regulaban en un aparte específico los acuerdos sobre medio ambiente, entendiendo por tales, aquellos en que las partes se comprometían a lograr una reducción de la contaminación o a cumplir determinados objetivos en el ámbito del medio ambiente, en particular, los enunciados en el artículo 174 del Tratado CE ${ }^{57}$.

Las Directrices establecían con claridad que el acuerdo debía tener como objetivo o como consecuencia la reducción de un agente contaminante o de un tipo de residuo en particular, prohibiendo aquellos acuerdos que generaran la reducción de la contaminación como un efecto colateral de otras medidas. En este último caso, si los acuerdos tenían efectos anticompetitivos no podían invocar la excepción y eran objeto de sanción.

Adicionalmente, de manera ejemplificativa se establecían ciertos tipos de acuerdos voluntarios tendientes a la protección del medio ambiente, entre ellos, los pactos de estandarización, los pactos a través de los cuales se fijaban normas sobre las cualidades ecológicas de los productos o procesos de producción, asî como los acuerdos en los que se manifestara expresamente un compromiso por lograr un objetivo medioambiental (reciclaje de ciertos materiales, reducción de emisiones o la mejora de la eficacia energética).

Por supuesto de cara a las normas de libre competencia la regulación y aceptación de los acuerdos ambientales solo resultaba relevante en cuanto ellos establecieran restricciones indebidas y prohibidas a la luz del artículo 81 del Tratado CE (actual artículo 101 del TFUE). En este orden, las Directrices señalaban los acuerdos voluntarios que no estaban cobijados por la prohibición general del artículo 81 del Tratado CE y que en consecuencia podían ejecutarse sin ninguna restricción ${ }^{58}$.

56 Comunicación de la Comisión de 6 de enero de 2001. Directrices sobre la aplicabilidad del artículo $81 \mathrm{del}$ Tratado CE a los acuerdos de cooperación horizontal. (DOCE 2001 C3/2, de 6 de enero) en adelante Directrices sobre acuerdos horizontales de 2001. 
En este categoría estaban por ejemplo los pactos que no imponían una obligación concreta a cargo de una de las partes o cuando éstas simplemente se comprometían a alcanzar un objetivo medioambiental vigente (legal o reglamentariamente) en todo un sector económico.

De la misma manera, se consideraba que aquellos acuerdos que establecían cualidades ecológicas de los productos o procesos y que no afectaban sensiblemente la diversidad de estos en el mercado de referencia o no incidían de forma determinante en el poder de compra, no debían considerarse restrictivos de la competencia, por ejemplo, cuando se excluían ciertas clases de un producto que solo representaba una escasa parte del mercado geográfico de referencia.

También se consideraban excluidos del análisis amparado por las Directrices los acuerdos de reciclaje siempre las partes no estuvieran en condiciones de realizar esta actividad de forma directa y no existieran otras alternativas ni otros competidores.

Las Directrices señalaban que frente a los acuerdos voluntarios con un claro objetivo de protección del medio ambiente pero que conllevaran una restricción del ejercicio de la libre competencia, impidiendo la entrada de nuevo actores, concentrando el mercado en unos pocos competidores, o bien, estableciendo una barrera de entrada al mismo, correspondía a la respectiva autoridad de competencia o al juez, determinar si dicho pacto encajaba dentro de los supuestos consagrados en el parágrafo 3 del artículo 81 del Tratado CE y, por ende, podía ejecutarse libremente en el mercado.

De conformidad con las Directrices el acuerdo medioambiental podía estar dentro de la prohibición general del apartado 1 del artículo 81 del Tratado CE si limitaba sensiblemente la capacidad de las partes para determinar las características de sus productos o de la cadena de producción, cuando eliminada una porción importante de las ventas de un competidor con una cuota de mercado considerable o cuando una empresa con una importante presencia en el mercado designaba a otra como prestador exclusivo de los servicios de recogida o reciclaje aun cuando existan otros proveedores reales o potenciales de tales servicios.

Para efectos de la aplicación del parágrafo 3 del antiguo artículo 81 del Tratado CE (hoy artículo 101.3 del TFUE), la Comisión sostenía que los acuerdos con fines ambientalmente positivos podían considerarse como pactos que implicaban un progreso técnico o económico y, por esta vía podían quedar exentos siempre que además cumpliera las siguientes condiciones; 1 ) Generaran una ventaja económica, 2) Que las restricciones impuestas tuvieran carácter indispensable y, 3) Que no eliminaran la competencia respecto de una parte sustancial de los productos y del mercado de que se trate ${ }^{59}$.

59 El acuerdo entonces debía representar unas ventajas económicas que compensaran los costes, es decir, los efectos negativos que produce sobre la competencia, ya sea desde la 


\section{Directrices sobre la aplicabilidad del artículo 101 Del TFUE A LOS ACUERDOS DE COOPERACIÓN HORIZONTAL DE 2011}

Para el año 2011 se publican las nuevas Directrices sobre acuerdos de cooperación horizontal ${ }^{60}$, a través de las cuales la Comisión complementa los Reglamentos de Exención por Categoría Reglamentos (EU) 1217/2010 y 1218/2010 y adicionalmente da claridad sobre cuáles acuerdos de cooperación se pueden considerar anticompetitivos y cuáles se consideran exceptuados del ámbito del artículo. 101 del TFUE.

La importancia de las Directrices radica en el hecho de que pueden existir acuerdos de cooperación que a pesar de no estar expresamente exceptuados en los Reglamentos pueden quedar eximidos a través de la aplicación del autoexamen, siempre que las partes constaten que se cumplen con las condiciones establecidas en el apartado 3 del artículo 101 del TFUE según las indicaciones y precisiones que brinda la Comisión sobre cada una de dichas condiciones y atendiendo el tipo de acuerdo.

Respecto de la valoración de los acuerdos voluntarios medioambientales estas Directrices de 2011 introducen grandes cambios. A diferencia de las Directrices de 2001, los pactos protectores del medio ambiente no se clasifican en un apartado y como una categoría independiente, sino que son abordados dentro de las diversas subespecies de acuerdos horizontales tales como los acuerdos de Investigación y Desarrollo ( $+\mathrm{D})$, los acuerdos de producción, los acuerdos de comercialización y de estandarización.

Lo antes señalado, implica que cuando estamos frente a un acuerdo voluntario de cumplimiento ambiental, o en general frente a acuerdo entre empresas que vulnere la libre competencia económica (esto es que encaje en el supuestos del apartado $1 \mathrm{del}$ artículo $101 \mathrm{del}$ TFUE) pero que se pretende amparar en la excepción, será necesario constatar que dicho Acuerdo satisface las finalidades perseguidas por el artículo $174 \mathrm{del}$ Tratado CE, las exigencias particulares que para cada una de las categorías o tipos de acuerdos horizontales se señalan y que además cumple los supuestos contenidos en el inciso 3 del artículo 101 del TFUE.

perspectiva individual de los consumidores o en su conjunto. Estos costes, incluyen, los efectos de una reducción de la competencia, junto con el valor que implica la ejecución del acuerdo para los agentes económicos.

El carácter indispensable estaba atado intrínsecamente con la eficiencia económica de un acuerdo medioambiental. Esta condición debía basarse en un análisis coste-beneficio, que permita demostrar que la utilización de otros medios alternativos y menos restrictivos supone mayores costos para los operadores económicos

Por último, el acuerdo no debía eliminar la competencia, en lo concerniente a los productos o los procesos de producción o a la entrada en el mercado a corto o medio plazo.

60 Directrices sobre la aplicabilidad del artículo 1010 del TFUE a los acuerdos de cooperación horizontal (2011/C 11/01). 
Las nuevas Directrices determinan que tanto los Acuerdos de Investigación y Desarrollo $(\mathrm{I}+\mathrm{D})^{61}$, como los acuerdos de producción ${ }^{62}$ y de comercialización $^{63}$ que se celebren entre empresas que están al mismo nivel de ubicación dentro del mercado, pueden incluir o incorporar de manera expresa o implícita la generación de política y beneficios para el medio ambiental.

Donde quizás se ha reconocida un mayor impacto de los acuerdos ambientales ha sido en la regulación de los denominados los acuerdos de estandarización, esto es, aquellos cuyo propósito es definir los requisitos técnicos o cualitativos que deben satisfacer los productos o procedimientos y métodos de producción actuales y futuros ${ }^{64}$. Es en ellos en los que se ha reconocido una mayor eficiencia en el objeto primordial de la tutela del medio ambiente, en especial, a través de los acuerdos de estándares sobre el rendimiento medioambiental de los productos ${ }^{65}$. Los pactos de estandarización, pueden traer concatenada la tutela de otros intereses, circunstancia que reforzaría su inclusión dentro del régimen de la excepción ${ }^{66}$.

En desarrollo del apartado 3 del artículo 101 del TFUE estos acuerdos entrarán en la exoneración en mención, cuando procuren mejoras de eficiencia, ya sea en forma de ahorro de costos o de mejores tecnologías de producción, y esta mejora puede referirse a aspectos de protección del medio ambiente en el ámbito propio de cada una de los tipos de acuerdos horizontales. Por ejemplo tratándose de acuerdo de producción conjunta las empresas pueden no sólo mejorar la calidad de sus productos sino lograr un ahorro en el consumo de agua y luz.

De lo señalado hasta aquí queda claro que el Derecho Europeo de la Competencia ha introducido una serie de beneficios para los acuerdos voluntarios de cumplimiento ambiental a tal punto que los mismos pueden constituir el

61 Directrices sobre Acuerdos Horizontales de 2011. Numeral 149. Los Acuerdo de I+ D comprende la subcontratación de algunas actividades de $\mathrm{I}+\mathrm{D}$, la mejora en común de alguna tecnología existentes, o una ayuda mutua en cuanto investigación, desarrollo y comercialización de productos completamente nuevos. En el ámbito de dichos acuerdo pueden desplegarse efecto positivo para el medio ambiente

62 Directrices sobre Acuerdos Horizontales de 2011. "Numeral 150. Los acuerdos de producción, se podrán manifestar de diversas maneras, podrán referirse a una de las partes o un número plural de ellas que realicen la producción, o pueden implicar la constitución de una empresa en participación, controlada conjuntamente, o, por último, se podrá manifestar en acuerdos de subcontratación".

63 Directrices sobre Acuerdos Horizontales de 2011. Numeral 225. "Estos acuerdos implican la cooperación entre competidores para la venta, distribución o promoción de sus productos sustitutivos (...)".

64 Directrices sobre Acuerdos Horizontales de 2011. Numeral 257.

65 Sobre el encasillamiento de estos acuerdos dentro de la excepción contemplada en el artículo 101 del TFUE numeral 3, en la directriz se manifiesta al respecto: Los estándares relativos a, por ejemplo, la calidad, la seguridad y los aspectos medioambientales de un producto pueden, por otra parte, facilitar la elección de los consumidores y dar lugar a una mayor calidad de los productos. Los estándares también desempeñan un cometido importante de cara a la innovación. Pueden reducir el tiempo necesario para introducir una nueva tecnología en el mercado y facilitar la innovación baciendo posible que las empresas se basen en soluciones acordadas.

66 Ver ejemplo 5 referido a los acuerdos de estándares medio ambientales. Numeral 329 
soporte de una exención en la medida en que los beneficios que arrojen sean mayores que la restricción que deriva de su aplicación.

Corresponde ahora revisar si en el ordenamiento de libre competencia colombiano los acuerdos medioambientales con efectos restrictivos podrían tener un trato más favorable en razón de los beneficios que los mismos persiguen o, si ellos están exceptuados legalmente de las normas antitrust y, por ende, las compañías y las autoridades deberían recurrir a ellos con más asiduidad.

\section{LA PROTECCIÓN DE LA LIBRE COMPETENCIA EN COLOMBIA Y SU COMPATIBILIZACIÓN CON LA PROTECCIÓN DEL MEDIO AMBIENTE}

\section{Marco Constitucional de protección a la libre COMPETEnCia}

La Constitución de 1991 introdujo importantes cambios en el sistema jurídico y económico colombiano ${ }^{67}$. Se destacan por su importancia y relación directa con el tema que ahora se aborda, la consagración de Colombia como Estado Social de Derecho y el establecimiento de una economía de mercado como base del sistema económico del país. Precisamente como manifestaciones del modelo de economía de mercado, la Constitución establece un conjunto de libertades y derechos de contenido económico y junto con ellos un principio de dirección general de la economía a cargo del Estado, con base en el cual éste ejerce sus facultades de intervención y regulación con propósitos específicos que fundamentalmente se encuentran encaminados a materializar los fines del Estado Social de Derecho.

Dentro de las varias libertades y derechos de contenido económico establecidos en la C.P. se encuentra la libertad económica y como manifestaciones de ella, la libre iniciativa privada, la libertad de empresa y la libre competencia económica ${ }^{68}$.

ARCHILA PEÑALOSA, Emilio José. "Antecedentes Constitucionales y Régimen de Prácticas Comerciales Restrictivas", Revista CEDEC -Centro de Estudios de Derecho de la Competencia-, Bogotá, Pontificia Universidad Javeriana, 1996, pp. 12 y 13 "La constituyente consideró que, a diferencia de lo que babía sucedido en 1886, pero en concordancia con la evolución posterior de esa constitución colombiana, los aspectos de manejo económico del país son materia de la ley de leyes y el constituyente no debe dejar la materia exclusivamente al desarrollo por el legislativo ordinario. En estas condiciones era propio incluir en la carta misma un mayor detalle en cuanto a los campos de acción del Estado en la economía e inclusive disposiciones sobre el sentido de ésta".

68 Corte Constitucional, Sentencia C-616 de 2001, M.P. Rodrigo Escobar Gil: "Se ba considerado que la libertad económica comprende los conceptos de libertad de empresa y libertad de competencia, que la Corte estima necesario examinar como fundamento de la providencia. (...) La libertad económica es expresión de valores de razonabilidad y eficiencia en la gestión económica para la producción de bienes y servicios y permite el aprovechamiento de la capacidad creadora de los individuos y de la iniciativa privada. En esa medida, la misma constituye un valor colectivo que ba sido objeto de especial protección constitucional. Adicionalmente la libertad económica permite también canalizar recursos privados, por la vía del incentivo económico, bacia la promoción de concretos intereses colectivos y la prestación de servicios públicos. En esa posibilidad se aprecia 
En este orden de ideas, puede afirmarse que la libre competencia es un derecho económico de orden constitucional cuyo contenido y alcance se establece en el art. 333 de la C.P. que al respecto dispone:
ARTICULO 333. La actividad económica y la iniciativa privada son libres, den- tro de los límites del bien común. Para su ejercicio, nadie podrá exigir permisos previos ni requisitos, sin autorización de la ley.
La libre competencia económica es un derecho de todos que supone responsabilidades. La empresa, como base del desarrollo, tiene una función social que implica obli- gaciones. El Estado fortalecerá las organizaciones solidarias y estimulará el desa- rrollo empresarial.
El Estado, por mandato de la ley, impedirá que se obstruya o se restrinja la libertad económica y evitará o controlará cualquier abuso que personas o empresas hagan de su posición dominante en el mercado nacional.
La ley delimitará el alcance de la libertad económica cuando así lo exijan el interés social, el ambiente y el patrimonio cultural de la Nación.

Lo primero que hay que destacar es que la libre competencia económica además de ser un derecho de orden constitucional es un principio de orden económico que debe orientar la actividad empresarial de los particulares y del Estado al igual que la intervención de éste dentro de la economía. Sobre este punto se destacan las consideraciones de las sentencias de la Corte Constitucional C-535 de $1997^{69}$ C-616 de $2001^{70}$, C-369 de $2002^{71}$, C-389

una opción, acogida por el constituyente, para bacer compatibles los intereses privados, que actúan como motor de la actividad económica, con la satisfacción de las necesidades colectivas".

Además del art. 333, que se refiere en forma expresa a la libre competencia como derecho colectivo, la C.P. contiene otra serie de normas que protegen y garantizan el ejercicio de otros derechos y libertades de contenido económico y que resultan necesarios para desarrollar el modelo de economía de mercado y en particular las libertades a las que se refiere el art. 333, entre ellas: La libertad para escoger profesión u oficio (art. 26), la libertad de asociación (art. 38 C.P.), la propiedad privada (art. 58) y el acceso a la propiedad y la participación de los trabajadores en los procesos de privatización (art. 64).

Corte Constitucional, Sentencia C-535 de 1997, M.P. Eduardo Cifuentes Muñoz: "La libre competencia adquiere el carácter de pauta o regla de juego superior con arreglo a la cual deben actuar los sujetos económicos y que, en todo momento, ba de ser celosamente preservada por los poderes públicos, cuya primera misión institucional es la de mantener y propiciar la existencia de mercados libres".

70 Corte Constitucional, Sentencia C-616 de 2001, M.P. Rodrigo Escobar Gil: "La competencia se presenta cuando un conjunto de empresarios (personas naturales o jurídicas), en un marco normativo, de igualdad de condiciones, ponen sus esfuerzos o recursos en la conquista de un determinado mercado de bienes $y$ servicios. La libertad de competencia supone la ausencia de obstáculos entre una pluralidad de empresarios en el ejercicio de una actividad económica lícita. (...). La Constitución contempla la libre competencia como un derecho. La existencia del mismo presupone la garantía de las mencionadas condiciones, no sólo en el ámbito general de las actividades de regulación atenuada, propias de la libertad económica, sino también en aquellas actividades sujetas a una regulación intensa pero en las cuales el legislador, al amparo de la Constitución, haya previsto la intervención de la empresa privada". Negrillas fuera de texto.

71 Corte Constitucional, Sentencia C-369 de 2002, M.P. Eduardo Montealegre Lynett: "Por 
de $2002^{72}$, C- 1125 de $2008^{73}$ y C-228 de $2010^{74}$, al igual que el concepto de la SIC No. 02007014 de 13 de marzo de $2002^{75}$.

La libre competencia es además un derecho colectivo ${ }^{76}$, es decir, que pertenece a la colectividad, dado que el correcto funcionamiento del mercado crea beneficios para todos los que en él participan y contribuye a incrementar el bienestar general. Debido a este carácter, puede protegerse a través del ejercicio de las acciones populares reguladas en la Ley 472 de 1998.

La libre competencia también tiene límites. En efecto, el propio art. 333 de la C.P. establece que "la libre competencia económica es un derecho de todos que supone responsabilidades" y luego en su inciso final destaca que "la ley delimitará el alcance de la libertad económica cuando así lo exijan el interés social, el ambiente y el patrimonio cultural de la Nación".

Según opinión de la Corte Constitucional, los límites que se imponen a la libre competencia, deben ser razonados, proporcionados, necesarios y no deben afectar el núcleo esencial del derecho, dada la importancia que éste tiene dentro del sistema de la economía de mercado. De esta forma a través de la

tanto, puede entenderse que la libre competencia se presenta cuando un conjunto de empresarios, en un marco normativo de igualdad de condiciones, invierten sus esfuerzos, en la conquista de un mercado determinado, bajo el supuesto de la ausencia de barreras de entrada o de otras prácticas restrictivas que dificulten el ejercicio de una actividad económica lícita. Bajo estas consideraciones la libre competencia económica, como un derecho individual y a la vez colectivo (CP art. 88), tiene como finalidad alcanzar un estado que permita la obtención del lucro individual para el empresario, y a la vez que genere beneficios para el consumidor con bienes y servicios de mejor calidad, con mayores garantías y a un precio real y justo".

72 Corte Constitucional, Sentencia C-389 de 2002, M.P. Clara Inés Vargas Hernández. Reitera lo dicho en sentencia C-616 de 2001.

73 Corte Constitucional, Sentencia C-1125 de 2008, M.P. Humberto Sierra Porto. Reitera lo dicho en sentencia C-616 de 2001.

74 Corte Constitucional, Sentencia C-228 de 2010, M.P. Luis Ernesto Vargas: "La Carta adopta un modelo de economía social de mercado, que reconoce a la empresa y, en general, a la iniciativa privada, la condición de motor de la economía, pero que limita razonable y proporcionalmente la libertad de empresa y la libre competencia económica, con el único propósito de cumplir fines constitucionalmente valiosos, destinados a la protección del interés general".

75 Concepto de la SIC No. 02007014 de 13 de marzo de 2002: "La Constitución Política en su artículo 33 establece como principios orientadores del Estado Social de Derecho colombiano la libertad de empresa y la libertad de competencia y el artículo 334 atribuye al Estado la dirección general de la economía. En virtud de estos principios, todas las personas tienen el derecho de concurrir al mercado dentro de un marco de competencia en el cual cada uno de los participantes lucha por atraer el mayor número de consumidores posible y en el evento de lograrlo, sus competidores ven disminuida la demanda de las prestaciones mercantiles que ofrecen. En desarrollo de lo anterior, si en la lucha por atraer a los consumidores se utilizan medios leales, quienes resultan vencidos en virtud del libre juego de la oferta y la demanda tienen la obligación de soportar dicho efecto. A contrario sensu, cuando dentro de esa lucha los competidores se valen de medios desleales que distorsionan el mercado, su conducta se bace reprimible".

76 C.P. "Artículo 88. La ley regulará las acciones populares para la protección de los derechos e intereses colectivos, relacionados con el patrimonio, el espacio, la seguridad y la salubridad públicos, la moral administrativa, el ambiente, la libre competencia económica y otros de similar naturaleza que se definen en ella". (Negrillas fuera de texto). 
jurisprudencial constitucional se han logrado conciliar los intereses colectivos con los intereses particulares, pues si de un lado se reconoce que el ejercicio de la libre competencia puede limitarse, de otro, se establece que los límites que se impongan para su ejercicio deben cumplir una serie de requisitos para evitar que el derecho desaparezca o pueda verse limitado en forma exorbitante ${ }^{77}$.

\section{EL INTERVENCIONISMO DEL ESTADO EN LA ECONOMÍA}

Paralelamente a la consagración de libertades y derechos de orden económico y de los mecanismos para su defensa, nuestro modelo reconoce y promueve la intervención del Estado en la Economía con miras a proteger y garantizar la efectividad de los principios y derechos que se desprenden del modelo de Estado Social de Derecho que consagra la C.P. de Colombia.

Bajo el nuevo modelo de Estado Social de Derecho que establece la C.P., a la vez que se reconocen y se protegen derechos económicos de naturaleza individual y colectiva se dispone la intervención del Estado con fines de redistribución y solidaridad, logrando -por lo menos hasta donde la aplicación del modelo permite afirmarlo- un equilibrio y un desarrollo general en ventaja de todos. En sentido la Corte Constitucional ha destacado la complementariedad entre las libertades económicas y el dirigismo de la economía ${ }^{78}$.

Corte Constitucional, sentencia C-535 de 1997: "5.3 El examen de estricta proporcionalidad de una disposición legal que injiere en la libertad de empresa, postula que la intervención debe fundarse en un bien, fin, o interés que exbiba una jerarquía constitucional por lo menos semejante a la libertad afectada y que la restricción sea necesaria y no represente para el titular del derecho costos o cargas excesivas, sin perjuicio, desde luego, de la función social que debe cumplir la empresa y de la observancia de los límites que a ésta señala el artículo 333 de la C.P.".

78 Corte Constitucional, sentencia C-265 de 1994, M.P. Alejandro Martínez Caballero: “(...) la Constitución colombiana, al consagrar un Estado social de derecho (C.P art 1), combina el intervencionismo económico -lo cual supone una permanente posibilidad de restricción estatal de las libertades económicascon el radical respeto de los derechos civiles y políticos -por lo cual la restricción de estos últimos debe tener fundamento expreso y específico-. En efecto, de un lado, la Constitución consagra una economía social de mercado dirigida, puesto que reconoce genéricamente que la iniciativa privada y la actividad económicas son libres (C.P art 332) pero establece, también de manera global, que "la dirección general de la economía estará a cargo del Estado" (C.P art 333). (...) Estas materias económicas constituyen entonces precisamente el ámbito en donde el interés general prima con claridad sobre el interés particular (C.P art 1 y 58 ), puesto que sólo limitando, de manera razonable y proporcional, las libertades económicas, puede el Estado contribuir a realizar un "orden político, económico y social "justo (preámbulo) y a bacer efectivos los llamados derechos bumanos de segunda generación o derechos prestacionales de las personas". En sentido similar, Corte Constitucional, sentencia C-040 de 1993, M.P. Ciro Angarita Barón: "Esta nueva forma de Estado, elevada a principio rector del comportamiento del poder público colombiano tiene como característica esencial en el plano económico la de legitimarlo para intervenir en las relaciones privadas de producción, a través de una política fundada en el principio de solidaridad y en el papel redistributivo del Estado. Dentro de este contexto y acompañada del principio de solidaridad, la libertad económica se entiende, no como el "dejar bacer dejar pasar", propio del Estado liberal clásico, sino como la promoción de las condiciones sociales y económicas básicas para el desarrollo autónomo de la persona. El Estado social de derecho no bace caso omiso de la falta de libertad que causa la miseria. Pero el nuevo concepto de libertad, no es simplemente 
Dentro de este marco general de intervención en la economía y precisamente para hacer efectivos los fines de mencionados en el artículo 334 de la C.P., el Estado a través de las normas de libre competencia garantiza el normal funcionamiento de los mercados y la competencia dentro de los mismos. En este orden de ideas, el régimen jurídico de prohibición de las prácticas restrictivas de la competencia constituye uno de los límites que se impone al ejercicio de esta libertad ${ }^{79} \mathrm{y}$ un mecanismo a través del cual el Estado pretende garantizar la existencia de las condiciones necesarias para que los agentes económicos actúen en forma libre y se deriven en favor de todos los beneficios de una libre y leal competencia dentro del mercado.

Adicional a los límites legales establecidos a través de las normas antimonopolio el Estado debe en aplicación del artículo 333 de la Constitución Política y en ejercicio de su deber de intervención en la economía privilegiar el interés social, el medio ambiente y el patrimonio cultural de la Nación. Esto significa que legalmente y por los motivos expuestos se pueden establecer límites o compromisos en el ejercicio de la libertad económica.

El ejercicio de cualquier actividad económica, puede encontrar limitantes en su desarrollo, es por ello, que el ordenamiento jurídico ha introducido excepciones y restricciones con miras de lograr la preservación de valores superiores por parte del Estado ${ }^{80}$. Y es que, el conjunto normativo a través del cual

formal $_{i}$ reivindica la posibilidad real de desarrollar actividades económicas libremente escogidas y autoriza al Estado para intervenir y crear las condiciones necesarias. Es bajo esta nueva concepción que se legitiman importantes instrumentos de intervención, tanto para la búsqueda de eficacia como de equidad. El papel del mercado como instrumento de asignación de recursos se concilia con el papel económico, político y social del Estado redistribuidor de recursos. Si damos, como lo quiere la Carta, valor jurídico a los principios constitucionales, no puede ser otra la interpretación del Estado colombiano actual. En este sentido, la tarea de los poderes públicos es la de generar una sociedad más justa y solidaria" (Negrillas fuera de texto). Este intervencionismo del Estado en la economía con fines particulares, es el resultado de los fracasos de los modelos absolutamente intervencionistas y de aquellos radicalmente liberales. Ni el Estado se encuentra en capacidad de asumir eficientemente la prestación de todos los servicios y de intervenir en todas las actividades, pero tampoco es posible creer que el mercado por sí mismo guiado de la "mano invisible" es capaz de crecer, lograr una distribución adecuada de recursos y evitar las distorsiones de la competencia

79 Concepto de la SIC No. 02064111 de 4 de septiembre de 2002. En el mismo sentido ver el concepto de la SIC No. 02106215 de 10 de enero de 2003 en el cual se afirmó: "el derecho a la competencia se constituye en un límite para el ejercicio de estas libertades de indole económico y en este orden de ideas, los agentes económicos no se encuentran legitimados para actuar de forma arbitraria en el mercado, sino que deben respetar las reglas que el legislador baya establecido en aras de proteger la libre competencia".

80 Sentencia C-228/10. M.P. Luis Ernesto Vargas Silva. Como se observa, el Estado Constitucional colombiano es incompatible tanto con un modelo del liberalismo económico clásico, en el que se proscribe la intervención estatal, como con modalidades de economía de planificación centralizada en las que el Estado es el unico agente relevante del mercado y la producción de bienes y servicios es un monopolio público. En contrario, la Carta adopta un modelo de economía social de mercado, que reconoce a la empresa y, en general, a la iniciativa privada, la condición de motor de la economía, pero que limita razonable y proporcionalmente 
se desarrollen los fines mencionados con anterioridad se deberá dar dentro de un marco de razonabilidad y proporcionalidad, y así, evitar la nugatoria total de la libertad que es objeto de limitación ${ }^{81}$.

Dentro de esas limitantes encontramos la protección y preservación del medio ambiente, establecida de manera explícita en el artículo 333 de nuestra Carta Política. El medio ambiente y su compatibilización con la libertad de competencia económica, involucra ciertas particularidades y matices singulares, en su doble matiz de derecho y deber constitucional que involucra al Estado y a los particulares.

En términos del artículo en mención, esta labor es encomendada al legislador, quien se ha instituido como la autoridad sobre la cual ha recaído la legitimación para el ejercicio de esta política. Las exigencias medioambientales configuradas como límites al ejercicio de la libre competencia deben plasmarse en normas jurídicas en principio, y estar concebidas o autorizadas por la ley.

Una de las manifestaciones de esta compaginación de intereses, se ha logrado mediante el establecimiento por parte del órgano legislativo de ciertos condicionamientos para la obtención de autorizaciones, tales como licencias, permisos, verificaciones ${ }^{82}$. Este tipo de restricciones, con carácter reglado, dan lugar a que verificado el cumplimiento de los supuestos fácticos de la norma, su concesión remueva una prohibición general que se ha producido con la exclusión del régimen de libre ejercicio de una cierta actividad económica ${ }^{83}$.

Sin embargo, a pesar de la existencia del mandato constitucional mencionado con anterioridad, se ha materializado la protección del medio ambiente a través de otros mecanismos legítimos, tal y como, la habilitación otorgada al juez constitucional. En esta autoridad ha recaído, de manera excepcional, la comenda de protección del ambiente sano, y es de recordar, que el medio ambiente, se ha instituido como un derecho colectivo, pero que, para su concreción en la mayoría de circunstancias ve su efectivo desarrollo a través de los derechos fundamentales de primer orden, tales como, la vida, la salud y la intimidad. En este sentido, la teoría de la conexidad ha permitido determinar el contenido de este derecho abstracto.

la libertad de empresa y la libre competencia económica, con el único propósito de cumplir fines constitucionalmente valiosos, destinados a la protección del interés general.

81 Sentencia Corte Constitucional C-978/10. M. P. Luis Ernesto Vargas Silva.

82 Sentencia C-815/01 M.P. Rodrigo Escobar Gil. De acuerdo con los artículos 333 y 334 de la Constitución Política, se reconoce y garantiza la libre competencia económica como expresión de la libre iniciativa privada en aras de obtener un beneficio o ganancia por el desarrollo y explotación de una actividad económica. No obstante, los cánones y mandatos del Estado Social imponen la obligación de armonizar dicha libertad con la función social que le es propia, es decir, es obligación de los empresarios estarse al fin social y a los limites del bien común que acompañan el ejercicio de la citada libertad.

83 Correa Henao, Magdalena. Libertad de Empresa en el Estado Social de Derecho. Ed. Universidad Externado de Colombia, 2008, p. 787 
En desarrollo de esta protección adicional, el juez constitucional en diversas decisiones judiciales ha determinado la protección del ambiente y por ende la limitación de la libertad de competencia atando sus pronunciamientos al cumplimiento de la norma legal que concreta el mandato constitucional. Es decir, se parte de la premisa legal que ha desarrollado la protección constitucional con el fin de resolver el asunto sometido a su competencia.

Así encontramos la sentencia T-536 de 1992, donde se tutela los derechos a un medio ambiente sano de las peticionarias, sobre la base del incumplimiento de los actos administrativos, que habían impuesto la obligación a una empresa productora de asfalto de adoptar las medidas pertinentes para reducir el nivel de contaminación del ambiente tanto del aire como del agua del río donde vertía sus desechos.

En este y en otros fallos la Corte Constitucional ${ }^{84}$, a pesar del grave incumplimiento por parte del empresario de las normas protectoras del medio ambiente, la Corporación no ha dejado de buscar una ponderación de los intereses contrapuestos -medio ambiente y libre competencia económicaimponiendo en algunos casos la obligación a la Administración la adopción de medidas tendientes al ajuste de la actividad económica a la legalidad ambiental y de salubridad exigida ${ }^{85}$.

De esta doctrina constitucional, también se ha desprendido el sometimiento del empresario a las normas ambientales y controles por la autoridad ambiental respectiva ${ }_{i}$ extendiendo aún más la obligación de la empresa, puesto que no basta, el cumplimiento de la normativa legal que regule la situación concreta, sino promulgando una efectiva y verídica protección del ambiente.

En este sentido, se presenta, pues, un cambio de paradigma que vincula al Estado, al consumidor y particularmente a la empresa en la problemática ambiental, mediante la compatibilización completa entre derechos relativos a la preservación y sostenibilidad y las libertades y derechos económicos, que pueden dar en caso soluciones específicas y balances diversos ${ }^{86}$.

Con el fin de que los límites legales no terminen siendo una negación de la libre competencia o de los mismos privilegien el medio ambiente en detrimento del legítimo ejercicio de la actividad empresarial, resulta necesario establecer si en Colombia al igual que en el ámbito europeo se ha planteado como necesaria la compatibilización de la actividad empresarial y la protección del medio ambiente estableciendo que dicha protección constituye un fin en sí mismo de manera que las empresas compitan dentro de los mercados proponiendo y mejorando los estándares ambientales en el desarrollo de sus procesos y productos. 
En paralelo resulta esencial examinar el régimen de prohibición y excepción de las conductas restrictivas en Colombia a fin de determinar si resulta viable invocar o solicitar la aplicación de una excepción respecto de las conductas restrictivas de la competencia que tengan como finalidad producir una mejora o incrementar la protección del medio ambiente. En resumen si los acuerdos voluntarios de cumplimiento ambiental que tengan efectos restrictivos de la competencia podrían exceptuarse tal y como ocurre en el sistema Europeo a partir de la aplicación del apartado 3 del artículo 101 del TFUE y de las Directrices que rigen la aplicación del artículo 101 del TFUC a los acuerdos de carácter horizontal.

\section{LA PROHIBICIÓN DE LAS CONDUCTAS RESTRICTIVAS DE LA COMPETENCIA Y EL SISTEMA DE EXCEPCIÓN}

En cuanto a la prohibición de las prácticas restrictivas de la competencia, Colombia sigue, por influencia del Derecho Europeo de la Competencia y del Derecho antitrust Estadounidense, un modelo que tiene como punto de partida el establecimiento de una prohibición general que se acompaña y armoniza con un régimen de exención o autorización.

Los artículos 1 de la Ley 155 de 1959 y 46 del Decreto 2153 de 1992 establecen la prohibición general de realizar prácticas restrictivas de la competencia dentro de los mercados ${ }^{87}$, así:

"Artículo 1 de la Ley 155 de 1959 modificado por el Decreto 3307 de 1963. Quedan prohibidos los acuerdos o convenios que directa o indirectamente tengan por objeto limitar la producción, abastecimiento, distribución o consumo de materias primas, productos, mercancías o servicios nacionales o extranjeros y en general toda clase de prácticas y procedimientos o sistemas tendientes a limitar la libre competencia y a mantener o determinar precios inequitativos".

"Decreto 2153 de 1992. Artículo 46. Prohibición.- En los términos de la ley 155 de 1959 y del presente decreto están prohibidas las conductas que afecten la libre competencia en los mercados, las cuales, en los términos del Código Civil, se consideran de objeto ilícito".

Por su parte, el artículo 2 de la Ley 1340 de 2009 que adicionó el artículo 46 del Decreto 2153 de 1992, señala expresamente que las normas de libre com-

87 Es preciso señalar que además de las normas en mención que se refieren al régimen general de libre competencia, algunos sectores económicos cuantas con disposiciones especiales aplicables en cuanto a la prohibición de las conductas restrictivas y el abuso de la posición de dominio. 
petencia se aplican respecto de todos los operadores económicos cualquier sea el sector o la actividad comercial que este ejecute dentro del mercado.

Artículo $2^{\circ}$. Ámbito de la ley. Adicionase el artículo 46 del Decreto 2153 de 1992 con un segundo inciso del siguiente tenor:

Las disposiciones sobre protección de la competencia abarcan lo relativo a prácticas comerciales restrictivas, esto es acuerdos, actos y abusos de posición de dominio, y el régimen de integraciones empresariales. Lo dispuesto en las normas sobre protección de la competencia se aplicará respecto de todo aquel que desarrolle una actividad económica o afecte o pueda afectar ese desarrollo, independientemente de su forma o naturaleza jurídica y en relación con las conductas que tengan o puedan tener efectos total o parcialmente en los mercados nacionales, cualquiera sea la actividad o sector económico".

Aunado a las normas anteriores el legislador colombiano también ha regulado, aunque en forma dispersa, el sistema de excepciones a la aplicación de las normas de libre competencia, esto es, los supuestos en los que las conductas bien sea por disposición legal o bien por autorización previa de autoridad competente, se sustraen de las prohibiciones señaladas y, en consecuencia, pueden ejecutarse sin que haya lugar a sanciones de ningún tipo.

\subsection{Excepción legal}

El artículo 49 del Decreto 2153 de 1992 establece un listado taxativo de los acuerdos que por disposición legal se consideran exceptuados de la prohibición general.

"Artículo 49. Excepciones.- Para el cumplimiento de las funciones a que se refiere el artículo 44 del presente decreto, no se tendrán como contrarias a la libre competencia las siguientes conductas:

1. Las que tengan por objeto la cooperación en investigaciones y desarrollo de nueva tecnología.

2. Los acuerdos sobre cumplimientos de normas, estándares y medidas no adoptadas como obligatorias por el organismo competente cuando no limiten la entrada de competidores al mercado;

3. Los que se refieran a procedimientos, métodos, sistemas y formas de utilización de facilidades comunes".

La excepción se fundamenta en que los efectos de estos acuerdos son por regla general pro-competitivos y benéficos para la economía y para el consumidor, en la medida en que contribuyen al desarrollo de nuevos productos o procedimientos que no podrían obtenerse ni implementarse sin el acuerdo anticompetitivo o cuya obtención se agiliza precisamente en razón del mismo. 
Este artículo introduce en nuestro ordenamiento jurídico algunas de las teorías que en el ámbito Europeo sustentan la expedición de Reglamentos de Exención por Categoría. Claramente los numerales 1, 2 y 3 del artículo 49 adoptan en Colombia las doctrinas Europeas que consideran exentos del régimen del art. 101.1 del TFUE, los acuerdos que tienen por objeto la cooperación, los acuerdos de investigación y desarrollo, los acuerdos de estandarización y los acuerdos de especialización (Reglamentos EU 1217/2010 y 1218/2010 de la Comisión y Directrices aplicables a los acuerdos de cooperación horizontal ${ }^{88}$.

Adicional a lo ya señalado, el artículo 31 de la Ley 1340 de 2009 dispuso que tampoco se aplican las normas de libre competencia a los mecanismos de intervención del Estado en la economía, esto es, a los Fondos de estabilización de precios, los Fondos Parafiscales para el Fomento Agropecuario, el Establecimiento de precios mínimos de garantía, la regulación de los mercados internos de productos agropecuarios prevista en el Decreto 2478 de 1999, los acuerdos de cadena en el sector agropecuario, el Régimen de Salvaguardias, y los demás mecanismos previstos en las Leyes 101 de 1993 y 81 de 1988.

Igualmente están por fuera del ámbito de aplicación de las normas restrictivas de la competencia según lo establecido en el inciso 2 del artículo 28 de la Ley 1340 de 2009, los institutos de salvamento y protección de la confianza pública ordenados por la Superintendencia Financiera de Colombia ni a las decisiones para su ejecución y cumplimiento.

En los casos señalados no será necesario que las empresas o agentes económicos obtengan una autorización previa para la ejecución de la conducta restrictiva como quiera que la exención opera por ministerio de la ley y de manera automática y en caso de que se inicie una investigación administrativa las empresas podrán invocar como defensa la aplicación del sistema de excepción legal.

\subsection{El sistema de autorización previa de las conductas restrictivas de la competencia}

Además de las excepciones de carácter legal, el ordenamiento colombiano reconoce que existen circunstancias bajo las cuales puede resultar necesaria la permisión y la autorización de determinadas conductas anticompetitivas (en su modalidad de acuerdos, convenios, concertaciones etc.). En estos casos, el

88 En relación con la aplicación del numeral 3 del artículo 49 del Decreto 2153 de 1992 puede verse la Resolución de la SIC No. 35741 de 2000 por medio de la cual se ordena la terminación de una investigación. En éste caso conocido como "Tasa Alaico" la SIC consideró que la tasa de cambio acordada entre las diferentes Aerolíneas para liquidar el valor de los pasajes aéreos respondía a la necesidad de dotar de seguridad éste tipo de transacciones y la necesaria utilización de sistemas de información comunes en favor de los operadores económicos y de los consumidores 
Estado en ejercicio de su facultad de intervención y regulación y, de acuerdo con los fines constitucionales que le han sido señalados para el ejercicio de estas funciones, puede autorizar ex ante la celebración de acuerdos anticompetitivos que resultan necesarios para la economía y, más concretamente, para la estabilidad de un sector básico de la producción de bienes o servicios ${ }^{89}$.

Al respecto el parágrafo del artículo 1 de la Ley 155 de 1959 establece lo siguiente:

"Artículo 1‥- (Modificado Artículo 1 Decreto 3307 de 1993) (...)

Parágrafo. El gobierno, sin embargo, podrá autorizar la celebración de acuerdos o convenios que no obstante limitar la libre competencia, tengan por fin defender la estabilidad de un sector básico de la producción de bienes o servicios de interés para la economía general".

Esta norma fue desarrollada por el art. 1 del Decreto Reglamentario 1302 de 1964 que estableció el alcance de la expresión "sectores básicos de la producción de bienes y servicios" ${ }^{\prime \prime 0}$ en términos tan amplios que convirtió la excepción en una válvula de escape para casi la totalidad de los sectores económicos.

Las normas mencionadas contienen un sistema análogo al de las exenciones individuales (que a día de hoy han desaparecido) y por categoría establecidas en el Derecho Europeo de la competencia ${ }^{91}$. Al igual que en este sistema jurídicos, a través de las autorizaciones el Gobierno Nacional exceptúa algunos acuerdos en particular o algunos sectores económicos de las reglas generales sobre prácticas restrictivas de la competencia, con el propósito de propender por la estabilidad económica de dichos sectores y de la economía en general.

Con el propósito de promover el acceso a este sistema y de brindar mayor seguridad a los operadores económicos en el tema, la SIC incorporó en la Circular 010 de 2001 (Circular Única), exactamente en el Titulo VII de esta norma, referente a la "Promoción de la Competencia", los requisitos indispen-

89 OCDE. Derecho y Política de la Competencia en Colombia. Examen Interpartes. 2009, pp. 33 y ss.

90 Decreto 1302 de 1964. "Artículo 1.- Para los efectos del parágrafo del artículo 1o de la ley 155 de 1959, considérense sectores básicos de la producción de bienes o servicios de interés para la economía general y el bienestar social, todas aquellas actividades económicas que tengan o llegaren a tener en el futuro importancia fundamental para estructurar racionalmente la economía del país y abastecerlo de bienes o servicios indispensables al bienestar general, tales como: El proceso de producción y distribución de bienes destinados a satisfacer las necesidades de la alimentación, el vestido, la sanidad y la vivienda de la población colombiana, La producción y la distribución de combustibles y la prestación de los servicios bancarios, educativos, de transporte, energía eléctrica, acueducto, telecomunicaciones y seguros."

91 No debe olvidarse que en el contexto Comunitario el Reglamento 1/2003 eliminó el sistema de autorizaciones individuales y lo sustituyo por el mecanismo de excepción legal y auto-examen conforme se explicó en el numeral 2.2. del Capítulo I de este escrito. 
sables para que los particulares puedan solicitar la autorización de acuerdos restrictivos $^{92}$.

En Colombia el sistema de autorizaciones sólo opera en forma previa a la celebración y la ejecución de un acuerdo restrictivo ${ }^{93}$ y los efectos de la autorización concedida se encuentran limitados por la autoridad de competencia (SIC) en cuanto a su contenido (sector o sectores afectados), sus efectos (normas inaplicadas) y en cuanto a su extensión (partes y duración del acuerdo) ${ }^{94}$.

Conforme a lo anterior también sería procedente un sistema de retiro de la autorización o excepción concedida cuando las condiciones que fueron consideradas al momento de su otorgamiento varíen en forma considerable afectando el adecuado funcionamiento del mercado o cuando las partes incumplan los términos de la autorización o excedan los límites establecidos por la autoridad para el desarrollo de la conducta restrictiva. Si con el incumplimiento o con el exceso se han vulnerado además las normas de libre competencia habrá lugar a iniciar en contra de las partes las investigaciones correspondientes.

En realidad son muy escasos los eventos en los que se ha aplicado el sistema de autorización previa ${ }^{95}$ y en los casos en que la SIC ha abordado la materia

92 Disponible en www.sic.gov.co.

93 Conforme lo señala el numeral 1.5. del Capitulo Primero del Título VII de la Circular Única "En ningún caso podrá solicitarse autorización para acuerdos o convenios en proceso de ejecución, ni podrá versar respecto de conductas que sean objeto de investigación, que bayan sido sancionadas o respecto de las cuales haya existido orden de terminación o compromiso de modificación". De la Cruz Camargo. Dionisio. Excepciones y exenciones particulares en la aplicación de la ley de protección de la competencia por parte de la Superintendencia de Industria y Comercio, Con-texto Revista de Derecho y Economía, 2010, No. 32, pp. 101-102.

94 Concepto de la SIC No. 03018596 del 23 de abril de 2003: "(...) es necesario precisar que en la autorización que eventualmente otorgue esta Superintendencia para la celebración de acuerdos o convenios bajo los lineamientos del parágrafo del artículo 1 de la ley 155 de 1959, se señalara claramente el marco dentro del cual se debe desarrollar dicho convenio. En este sentido, la celebración del acuerdo o convenio no implica una autorización general para vulnerar los disposiciones sobre prácticas comerciales restrictivas, en tanto de lo que se trata es de la inaplicación de normas específicas, dada la necesidad de defender la estabilidad de un sector básico de la producción de bienes o servicios de interés para la economía general. Así las cosas, y en tanto los peticionarios están obligados a individualizar las normas específicas cuya inaplicación temporal pretenden, en caso de que se conceda la autorización para celebrar el acuerdo, la misma sólo se aplica frente a las normas y condiciones expresamente señaladas, bajo el supuesto de que no obstante limitar la libre competencia tienen la finalidad indicada en la citada ley. Por lo tanto en el evento en que se incurra en una práctica no prevista en el marco del acuerdo o convenio autorizado por esta Entidad la Superintendencia de Industria y Comercio estaría facultada para iniciar la investigación pertinente e imponer de ser el caso las sanciones a que baya lugar (...) Sobre el particular le reiteramos que la autorización concedida por esta Superintendencia no implica permiso para quebrantar legítimamente las disposiciones sobre prácticas comerciales restrictivas y abuso de posición dominante, en la medida en que se trata de una autorización excepcional con un alcance determinado que obliga a los intervinientes del acuerdo o convenio a observar cabalmente todas aquellas disposiciones que esta Superintendencia expresamente no le autorizó a inaplicar temporalmente en virtud de dicho acuerdo o convenio".

95 Varios son en mi parecer los factores por los cuales el parágrafo del art. 1 de la Ley 155 de 1959 y las normas que lo desarrollan no han sido aplicados: En primer lugar y quizás 
lo ha hecho para explicar el alcance de las normas y no para dar efectiva aplicación a las mismas ${ }^{96}$

Uno de los precedentes sobre el sistema de autorizaciones se encuentra en la investigación preliminar realizada por la SIC con ocasión de la queja presentada contra el "Convenio Marco para la absorción y el suministro de la producción de Aceite de Palma Africana"97. En el auto de 2 de junio de 1995 la SIC consideró

como el factor más importante aparece el desconocimiento de las normas de libre competencia en general y desde luego de aquellas que establecen el régimen de autorizaciones en particular $r_{i}$ en segundo lugar y como consecuencia del primero, se encuentra la falta de antecedentes sobre la aplicación de las disposiciones que regulan el tema; en tercer lugar, la falta de una cultura de competencia en virtud de la cual se prefiera obtener autorizaciones que brindar garantías en el curso de las investigaciones por prácticas restrictivas de la competencia; en cuarto lugar, la dificultad de probar los requisitos establecidos en el Capítulo I del Título VII de la Circular Básica de la SIC y, finalmente, la falta de claridad sobre los casos en los cuales además de la autorización de la SIC puede resultar necesaria la autorización de otra autoridad competente en materia de libre competencia.

96 Concepto 01078466 de 22 de octubre de 2001 "No obstante la prohibición señalada, el parágrafo del arriba citado artículo 1 de la ley 155 de 1959 contempla la facultad para el Gobierno Nacional, en cabeza de la Superintendencia de Industria y Comercio de "autorizar la celebración de acuerdos o convenios que no obstante limitar la libre competencia, tengan por fin defender la estabilidad de un sector básico de la producción de bienes o servicios de interés para la economía general.". En concordancia, el artículo 1 del decreto 1302 de 1964 señala que para efectos de la anterior disposición, se considera, entre otros, como sector básico de la economía general y el bienestar social, la prestación de servicios de transporte. Así las cosas, concluimos que en principio, un acuerdo de fijación de tarifas para el transporte por carretera como el que usted plantea está probibido, pero si cumple con los requerimientos señalados tanto por la ley 155 de 1959 como por el decreto 1302 de 1964, podrá solicitarse a esta Superintendencia que autorice su celebración. Aclaramos que para tomar una decisión, esta Superintendencia deberá como ya se dijo, constatar que el acuerdo planteado cumple con los requisitos legalmente establecidos para que proceda su autorización". Concepto 02064111 del 4 de septiembre de 2002: "Finalmente, es preciso anotar que, al tenor del parágrafo del artículo 1 de la ley 155 de 1959, "el Gobierno, sin embargo, podrá autorizar la celebración de acuerdos o convenios que no obstante limitar la libre competencia, tengan por fin defender la estabilidad de un sector básico de la producción de bienes o servicios de interés para la economía general. De conformidad con lo anterior y teniendo en cuenta que, según el artículo segundo del decreto 3307 de 1963, para efectos de la ley 155 de 1959, las funciones atribuidas al Gobierno son competencia de la Superintendencia de Industria y Comercio, se concluye que, en el evento en que un acuerdo restrictivo de la competencia tenga los fines señalados por dicho parágrafo, las partes deberán solicitar a esta Entidad, autorización para su celebración. Finalmente es necesario precisar que, en el capítulo primero del título VII de la circular externa 10 de 2001 (circular única) se establecen los criterios en los que se basa la Superintendencia a efectos de analizar la petición tendiente a obtener la autorización de este tipo de convenios y se instruye a quienes soliciten dicha autorización sobre la información que debe suministrarse para que la Entidad pueda pronunciarse al respecto".

97 El tema fue abordado por la SIC en el auto de 2 de junio de 1995, en el cual se destacan las consideraciones sobre la Constitución Económica Colombiana y los fines de la intervención Estatal, a partir de los cuales la SIC realiza un cuidadoso examen de las normas que regulan las prácticas restrictivas de la competencia en Colombia señalando que "entre las normas legales sobre intervención económica tiene un lugar especial la contenida en el parágrafo del artículo $1^{\circ}$ de la Ley 155 de 1959, por la cual se dictan algunas disposiciones sobre prácticas comerciales restrictivas, en virtud de la cual el Gobierno Nacional podrá autorizar la celebración de acuerdos o convenios que no obstante limitar la libre competencia, tengan por fin defender la estabilidad de un sector básico de la producción 
que el convenio "quedaba cobijado o amparado por el parágrafo del art. 1 de la Ley 155 de 1959 y que el acuerdo no gozaba de tipicidad a la luz de las normas de libre competencia, toda vez que según lo exigía el art. 4 del Decreto 2153 de 1992 los acuerdos debían celebrarse por "agentes económicos" requisito no se cumplía en el caso mencionado pues en la suscripción del Convenio había participado el Gobierno Nacional a través de los Ministros de Agricultura y Desarrollo Rural, Desarrollo Económico, Comercio Exterior y Hacienda y Crédito Público.

En el año 2003 la SIC aplicó por primera vez el parágrafo del artículo 1 de la Ley 155 de 1959 a un acuerdo entre empresas textileras ${ }^{98}$ y nuevamente lo hizo de nuevo en el Tema del convenio del Ministerio para vivienda de protección oficial.

En el año 2009 atendiendo lo señalado en cuanto al sistema de autorizaciones singulares el legislador Colombiano estableció en el artículo 5 de la Ley 1340 de 2009 que el sector agrícola es un sector básico de la economía, de forma tal que en relación con el mismo puede concederse la autorización; sin embargo la norma no asignó en este caso la competencia a la Superintendencia de Industria y Comercio sino al Ministerio de Agricultura ${ }^{99}$.

Para algún sector de la doctrina la excepción del sector agrícola constituye un claro ejemplo de una exención de bloque similar a la que se aplica en el contexto europeo.; otros autores por el contrario señalan que en realidad es una exención atípica o propia de nuestro sistema jurídico como quiera que la misma está sujeta al concepto previo del Ministerio de Agricultura y no de la autoridad de competencia y en ningún caso la exención se encuentra condicionada al cumplimiento de requisitos previos como si ocurre en Europa en cada uno de los Reglamentos de Exención por Categoría ${ }^{100}$.

Solo resta por decir que es de gran importancia que los operadores económicos conozcan y hagan uso del mecanismo de autorización previsto en el parágrafo del art. 1 de la Ley 155 de 1959, pues a través del mismo se puede obtener la autorización para celebrar de acuerdos restrictivos que tengan fines proteccionistas y/o competitivos para un sector determinado y obtener a través

de bienes o servicios de interés para la economía general", precisando además que "(...) esta norma se encuentra vigente, porque es totalmente compatible con lo dispuesto en los artículos 333, inciso final, y 334 de la Constitución Nacional".

98 Resolución 04332 de 25 de febrero de 2003

99 Artículo $5^{\circ}$. Aplicación del Régimen General de Competencia en el Sector Agrícola. Para los efectos del parágrafo del artículo $1^{\circ}$ de la Ley 155 de 1959, considérese como sector básico de interés para la economía general, el sector agropecuario. En tal virtud, el Ministerio de Agricultura y Desarrollo Rural deberá emitir concepto previo, vinculante y motivado, en relación con la autorización de acuerdos y convenios que tengan por objeto estabilizar ese sector de la economía.

100 De la Calle Restrepo, José Miguel. La mal llamada excepción de bloque en el régimen de competencia [en línea], [citado el 2 de abril de 2015]. http://www.dlplegal.co/dlp/en/ node $/ 38$. 
de ellos ventajas en los mercados subregionales, regionales e internacionales; además un desarrollo adecuado y progresivo de este mecanismo permite identificar las conductas que siendo restrictivas deben autorizarse y por tanto respecto de las cuales debe reformularse el alcance de la prohibición general sobre prácticas restrictivas. Solo una evolución sobre el sistema de autorizaciones permitirá que a futuro se pueda establecer un mecanismo de exención legal como el que hoy existe en el escenario Europeo.

\section{LA REGULACIÓN DE LOS ACUERDOS VOLUNTARIOS DE CUMPLIMEINTO AMBIENTAL EN COLOMBIA Y SU VALORACIÓN A LA LUZ DE LAS NORMAS DE LIBRE COMPTENCIA}

En el ordenamiento Colombiano no existe una definición legal de Acuerdos voluntarios de cumplimiento ambiental. No obstante, dentro de las políticas de protección promovidas por el Ministerio de Medio Ambiente se han reconocido las ventajas de los instrumentos de autorregulación y de responsabilidad social ${ }^{101}$.

En este contexto se reconoce como una modalidad de acuerdos ambientales los denominados acuerdos de producción más limpia (en adelante APML), que hasta el momento se han celebrado entre distintos gremios económicos con la ayuda y bajo la orientación del Ministerio ${ }^{102}$.

Estos acuerdos pretenden aumentar la competitividad de las empresas a partir del cumplimiento de fines relacionados con la protección del medio ambiente ${ }^{103}$

101 Ministerio del Medio Ambiente de Colombia. Política Nacional de Producción más Limpia, [en línea] 1997, [citado el 3 de abril de 2015] https:/www.minambiente.gov.co/images/ BosquesBiodiversidadyServiciosEcosistemicos/pdf/Normativa/Politicas/polit produccion_mas_limpia.pdf. Política Nacional de Producción y sostenible [en línea] 2011 [citado el 3 de abril de 2015] https://www.minambiente.gov.co/images/AsuntosambientalesySectorialyUrbana/pdf/compras_p\%C3\%BAblicas/polit_nal_produccion_consumo_sostenible. pdf.

102 Ministerio del Medio Ambiente de Colombia. Política Nacional de Producción y sostenible [en línea] 2011[citado el 3 de abril de 2015] https://www.minambiente.gov.co/images/ AsuntosambientalesySectorialyUrbana/pdf/compras_p\%C3\%BAblicas/polit_nal_produccion consumo sostenible.pdf."Convenios o acuerdos ambientales voluntarios: Se definen como acuerdos establecidos por los sectores productivos, a través de sus gremios y empresas, resultado de la concertación con autoridades públicas. Son explícitamente reconocidos por las autoridades. En ellos se establecen compromisos para el desarrollo de acciones y proyectos para el logro de los objetivos definidos concertadamente. Dentro el marco de esta política, los convenios de producción más limpia (PML) son denominados Agendas Ambientales".

103 Consejo Nacional de Producción Limpia. Acuerdos de Producción Limpia [en línea], 2005 [Citado 2 de abril de 2015] http://www.cpl.cl//p. 21 "reducción de emisiones, calidad ambiental, minimización, recuperación o reciclaje de residuos, reducción o eliminación de determinadas sustancias o materiales, eficiencia energética, higiene laboral, recopilación de información y abatimiento y disposición final. 
e incrementar la aceptación y cumplimiento de estándares productivos más exigentes. Sobre el particular el Ministerio del Medio Ambiente ha señalado:

"(...) para mejorar el desempeño ambiental de los sectores productivos, diversos gobiernos de todo el mundo promueven la producción más limpia como una estrategia complementaria a los instrumentos regulatorios. El principio central de la estrategia de producción más limpia y conceptos asociados como el de ecoeficiencia, consideran que la contaminación y la acelerada pérdida de recursos naturales constituyen un indicador de ineficiencias en la producción y en el uso de productos y servicios. En la medida en que estas ineficiencias son evitadas a través de la instrumentación de alternativas preventivas, los sectores mejoran su desempeño ambiental y al hacerlo, obtienen beneficios económicos". (Negrita fuera del texto)-

Pese a los beneficios que desde el Ministerio se atribuyen a los APML la autoridad insiste en que aún hoy día las empresas en Colombia no perciben como un beneficio directo los ventajas que derivan de una producción ambientalmente amigable, lo cual supone el reto de establecer desde la educación que los costos que asuma la empresa implica mejorar su posición y sus estrategias en un mercado en el que los estándares tienden a ser cada día más exigentes ${ }^{104}$.

De otra parte, el Ministerio evidencia en sus estudios que los consumidores en Colombia no valoran como un factor determinante de sus compras y elecciones la calidad ambiental de los productos, de manera que, también en este ámbito se hace necesario la intervención del Estado a través de educación a fin de que las empresas vean materializados los beneficios de su conducta en el incremento de sus ventas ${ }^{105}$.

Ahora bien, lo que si resulta claro del estudio hecho por el Ministerio sobre consumo sostenible es que existe una relación directa entre dicho consumo y la competitividad y productos. De manera que es importante que las empresas asuman como factor de competencia y fortalecimiento en el mercado

104 Ministerio del Medio Ambiente de Colombia. Política Nacional de Producción y sostenible... op. cit p. 17 "Ligado a lo anterior, aún persiste en una parte del sector productivo la percepción de que invertir en mejoramiento ambiental es un gasto y que la restitución de los recursos que allí se invierten es de difícil recuperación, ignorando o desconociendo que un bajo desempeño ambiental limita sus posibilidades de crecimiento, en un mercado cada vez más competitivo y globalizado".

105 Ibídem p. 24 "La encuesta muestra que la calidad ambiental es tan sólo uno de los argumentos que los consumidores toman en cuenta al adquirir un producto, por lo cual, la sensibilidad de los consumidores al considerar la calidad ambiental es aún limitada. Otros datos del MAVDT muestran que el mercado nacional de productos ecológicos es aún incipiente y sólo existen avances a nivel de programas demostrativos que involucran micro y pequeñas empresas y cooperativas de campesinos. Durante el año 2006 se vendieron más de 362.000 unidades, que representaron ventas por aproximadamente COP\$982 millones, a través un convenio de colaboración suscrito por el Ministerio y supermercados de grandes superficies". 
el cumplimiento de estándares ambientales incluso por encima de los niveles exigidas legal y reglamentariamente ${ }^{106}$.

Lo que no se ha discutido hasta el momento ni se ha planteado controversia alguna, es respecto a los efectos de los acuerdos voluntarios, que limiten o puedan llegar a restringir la competencia, en particular, el acceso o permanencia dentro de un mercado determinado.

A nuestro juicio dado el marco legal de las excepciones legales y singulares dentro del ordenamiento Colombiano dichos pactos pueden quedar inmersos en acuerdos de colaboración, de intercambios de información, producción, comercialización o estandarización a los cuales les resulta aplicable lo dispuesto en el artículo 49 del Decreto 2153 de 1992 y lo señalado en el parágrafo del artículo 1 de la Ley 155 de 1959 siempre que se demuestre que estamos en un sector básico de la economías. Nada obsta y sería lo ideal, que expresamente se concediera una exención para aquellos acuerdos que no obstante limitar la libre competencia también generan una serie de beneficios medio ambientales justifican su legalidad y ejecución.

\section{CONCLUSIONES}

La protección al medio ambiente se ha convertido en una meta en del derecho de la libre competencia económica. Para garantizar esta finalidad se buscan incrementar el cumplimiento de estándares de protección al medio ambientes se incorporen dentro de los costos empresariales, que los empresarios puedan recuperar las inversiones hechos a través de una mayor numero de ventas y el incremento de su cuota de mercado y que por esta vía decidan autónomamente y con una menor intervención del Estado elevar más los estándares de cumplimiento ambiental.

106 Ibídem p. 30 "La relación entre la competitividad y la producción y el consumo sostenible es directa en la medida en que las empresas que adoptan alternativas preventivas, innovan en sus procesos y productos $y$ obtienen beneficios económicos y ambientales a través de ellos. Estos beneficios muy seguramente generarán ventajas competitivas en el mercado, que son reconocidas por los clientes. Estas ventajas no son las mismas para todas las empresas. De acuerdo con sus particularidades, el tipo de negocio de que se trate o el sector, se puede distinguir: (i) mayor valor agregado de productos (costo - beneficio), (ii) estrategia para enfrentar competidores, facilitando la estandarización de procesos, (iii) aborro en los costos, por la eliminación de ineficiencias y la instrumentación de buenas prácticas, (iv) gestión del riesgo, que evita costos por accidentes e incumplimientos, (v) redefinición de mercados, que incorpora un cambio en el enfoque del negocio bacia la sostenibilidad ambiental y, (vi) innovación en los procesos y las materias primas empleadas". 


\section{BIBLIOGRAFÍA}

NORMAS Y DOCUMENTOS DEL SOFT LAW COMUNITARIO EUROPEO

\section{Libros y capítulos de libro}

Alonso Soto, Ricardo, El interés público en la defensa de la competencia. Martínez Lage, Santiago y Petitbó Juan, Amadeo (Dirs.). La modernización del Derecho de la Competencia en España y la Unión Europea. Madrid: Marcial Pons, 2005.

Baylos Corroza, Hermenegildo, Tratado de Derecho Industrial, Madrid: Civitas, 1993.

Bercovitz, Alberto, Apuntes de Derecho Mercantil.

Broseta Pont, Manuel. Manual de Derecho Mercantil. Madrid: Tecnos, 2007, 14ª Edición. Vol. I, 2007.

De Eizaguirre, José María, Derecho Mercantil, Madrid: Thomson Civitas, 2005, $4^{\mathrm{a}}$ Ed.

Garrigues, Joaquín, La defensa de la competencia mercantil, Madrid: Sociedad de Estudios y publicaciones, 1964

Guidini, Gustavo, Aspectos Actuales del Derecho Industrial. Propiedad Intelectual y Competencia, Granada: Comares, 2002.

Illescas, Rafael, Derecho de la competencia: La libre competencia. Jiménez Sánchez Guillermo J. (coord.), Derecho Mercantil, Barcelona: Ariel, 2006, 11 ª Ed., capítulo 38.

Illescas, Rafael. El campo de aplicación del Derecho de la Competencia. Los instrumentos jurídicos de aplicación. Beneyto, José María y Maillo González Orus, Jerónimo (Dirs.), Tratado de derecho de la competencia Unión europea y España, Tomo I, Madrid: Bosch, 2005.

Parejo Alfonso, Luciano, El nuevo sistema de defensa de la competencia. Algunas cuestiones generales sobre su fundamento constitucional y su organización específica en una administración independiente. Parejo Alfonso, Luciano y Palomar Olmeda, Alberto., Derecho de la competencia. Estudios sobre la Ley 15/2007, de 3 de julio, de Defensa de la Competencia, Madrid: La Ley, 2008.

Rincón García Loygorri, Alfonso, Las conductas prohibidas. Beneyto, José María y Maillo, Jerónimo (Dirs.), La nueva ley de defensa de la competencia. Análisis y comentarios. Barcelona: Bosch, 2009.

Robles Martín- Laborda, Antonio, Libre competencia y competencia desleal, Madrid: La Ley, 2001, $1^{\text {a }}$ Ed. 


\section{Artículos de revista y publicaciones de internet}

Calvo, Caravaca, Alfonso-Luis y Férnandez de la Gándara, Luis, Reflexiones en torno al concepto y funciones del derecho de la competencia. Boletín de la Gaceta Jurídica de la CE y de la Competencia, B- 85, 1993, pp. 13-22.

Calvo Caravaca, Alfonso-Luis y Fernández De La Gándara, Luis. Política y Derecho de la Competencia en la C.E.E: Una aproximación. Revista General del Derecho, No. 583, 1993, pp. 3378-3447.

De la Calle Restrepo, José Miguel. La mal llamada excepción de bloque en el régimen de competencia [en línea], [citado el 2 de abril de 2015]. http://www.dlplegal.co/ dlp/en/node/38.

De la Cruz Camargo. Dionisio. Excepciones y exenciones particulares en la aplicación de la ley de protección de la competencia por parte de la Superintendencia de Industria y Comercio, Con-texto Revista de Derecho y Economía, 2010, No. 32, pp. 97-113.

Delmas, Magali A. Terlaak, Ana K. A Framework for analyzing environmental voluntary agreeents. California Law Reiew, 2001, vol. 43, pp. 44-62.

Díez Estella, Fernando. Los objetivos del derecho antitrust. Gaceta Jurídica de la Unión Europea y la Competencia, No. 224, 2003, pp. 32 a 52.

Font Galán, Juan Ignacio, Notas sobre el modelo económico de la constitución española de 1978, Revista de Derecho Mercantil, No. 151, 1979, pp. 205-239.

Fikentscher, Wolfgang. Las tres funciones del control de la economía (Derecho Antimonopolio). Revistas de Derecho Mercantil, Nos. 172-173, 1984, pp. 459 a 486;

Ortiz Blanco, Luís y León Jiménez, Rosario, Aplicación de las normas de defensa de la competencia a las grandes superficies de distribución minorista, Revista de Derecho, [en línea], VLEX - TR331, [Citada 15 de enero de 2014] http://www.vlex.com.

Pascual y Vicente, Julio. Fundamentos y limitaciones de la defensa pública de la competencia. Gaceta Jurídica de la Unión Europea y la Competencia, marzo-abril, No 224, 2003, pp.

Sainz Moreno y Fernando. Orden público y restricciones de la competencia, Revistas de las Administraciones Públicas, No. 84, 1977, pp.597-640.

Sainz Moreno, Fernando, El principio de libre competencia como manifestación del orden público económico, Revistas Española de Derecho Administrativo, No. 24, 1980, pp. $134-138$. 
Joy Kingston, Suzzane Elizabeth. The role of Environmental Protection EC Competition Law and Policy. Tesis Doctoral. [en línea], 2009 [Citado el: 10 de febrero de 2015] https://openaccess.leidenuniv.nl/bitstream/handle/1887/13497/Suzanne\%20 Kingston\%20PhD\%20Thesis.pdf? sequence $=1$.

Rojo, Ángel. Actividad económica pública y actividad económica privada en la constitución española. Revista de Derecho mercantil, Nos. 169-170, julio-diciembre, 1983, pp. 309-341.

Uría Fernández, Francisco. Las consecuencias jurídico-privadas de las conductas contraria a la ley de defensa de la competencia, Aportaciones de la Ley 52/1999, de 28 de diciembre, de reforma de la ley de defensa de la competencia, AdC, 1999, pp.

Vedder, Hans H.B. Voluntary Agreements and Competition Law. Fondazione Eni Enrico Mattei. [en línea] [Citado el 20 noviembre de 2014] http://www.feem.it/ userfiles/attach/Publication/NDL2000/NDL2000-079.pdf

Weitz, Nurit. Libre comercio vs. Protección Ambiental: Un debate para Suramérica. South america business fórum, [en línea] 2011 [citado el 8 de octubre de 2014] http:// www.sabf.org.ar/assets/files/essays/Libre\%20comercio\%20vs\%20Proteccion $\% 20$ ambiental2.pdf

\section{OTROS NOTICIAS Y DOCUMENTOS}

Acuerdos de Producción Limpia: Gestión y Práctica [en línea], 2003 [Citado el: 10 de febrero de 2015] www.dialnet.unirioja.es.

Consejo Nacional de Producción Limpia. Acuerdos de Producción Limpia [en línea], 2005 [Citado 2 de abril de 2015] http://www.cpl.cl/ 